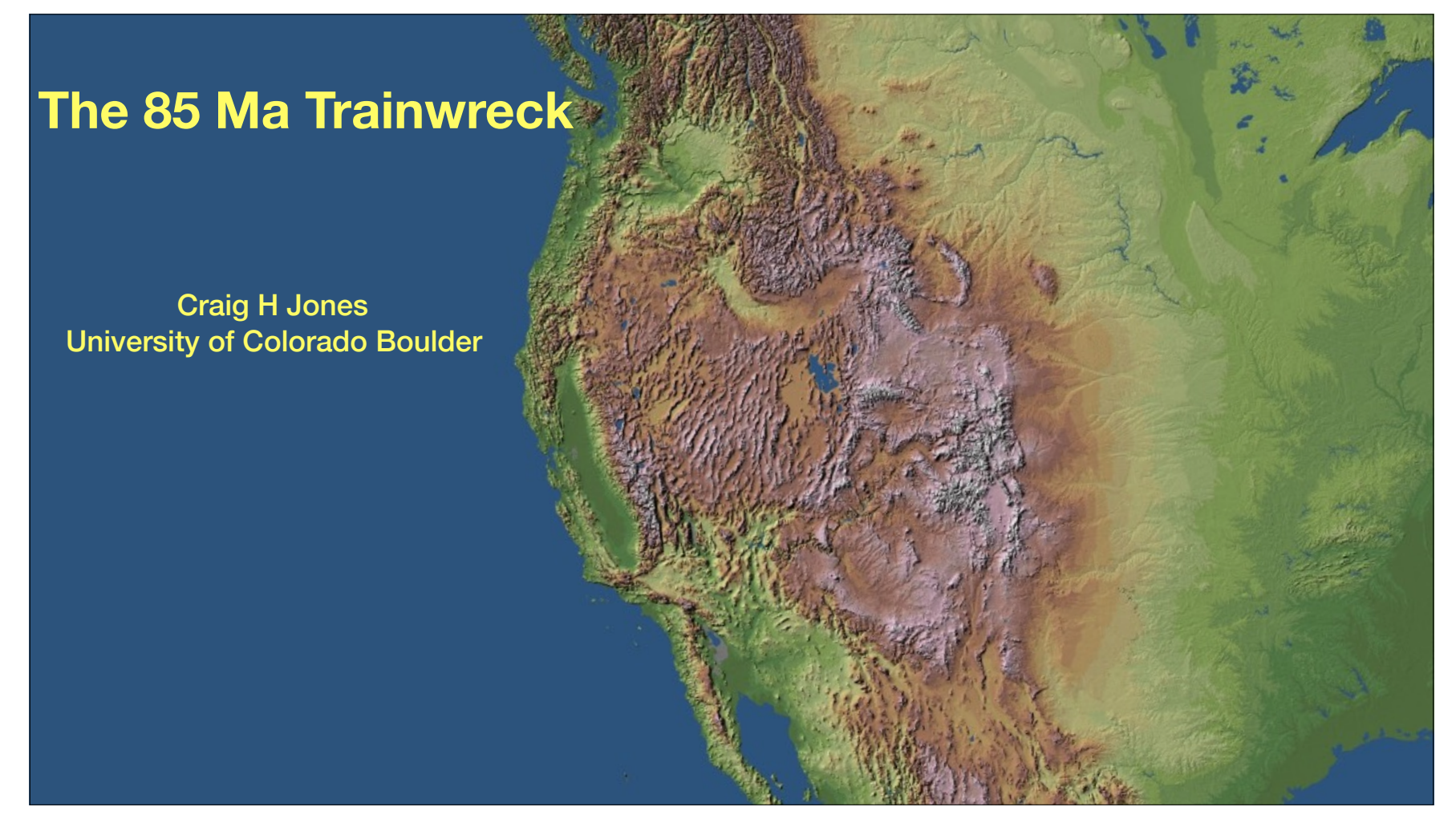

Widest non-collisional orogen. $85 \mathrm{Ma}$ is a tipping point-before all looks very Andean. Is throwing a plateau at it enough? 


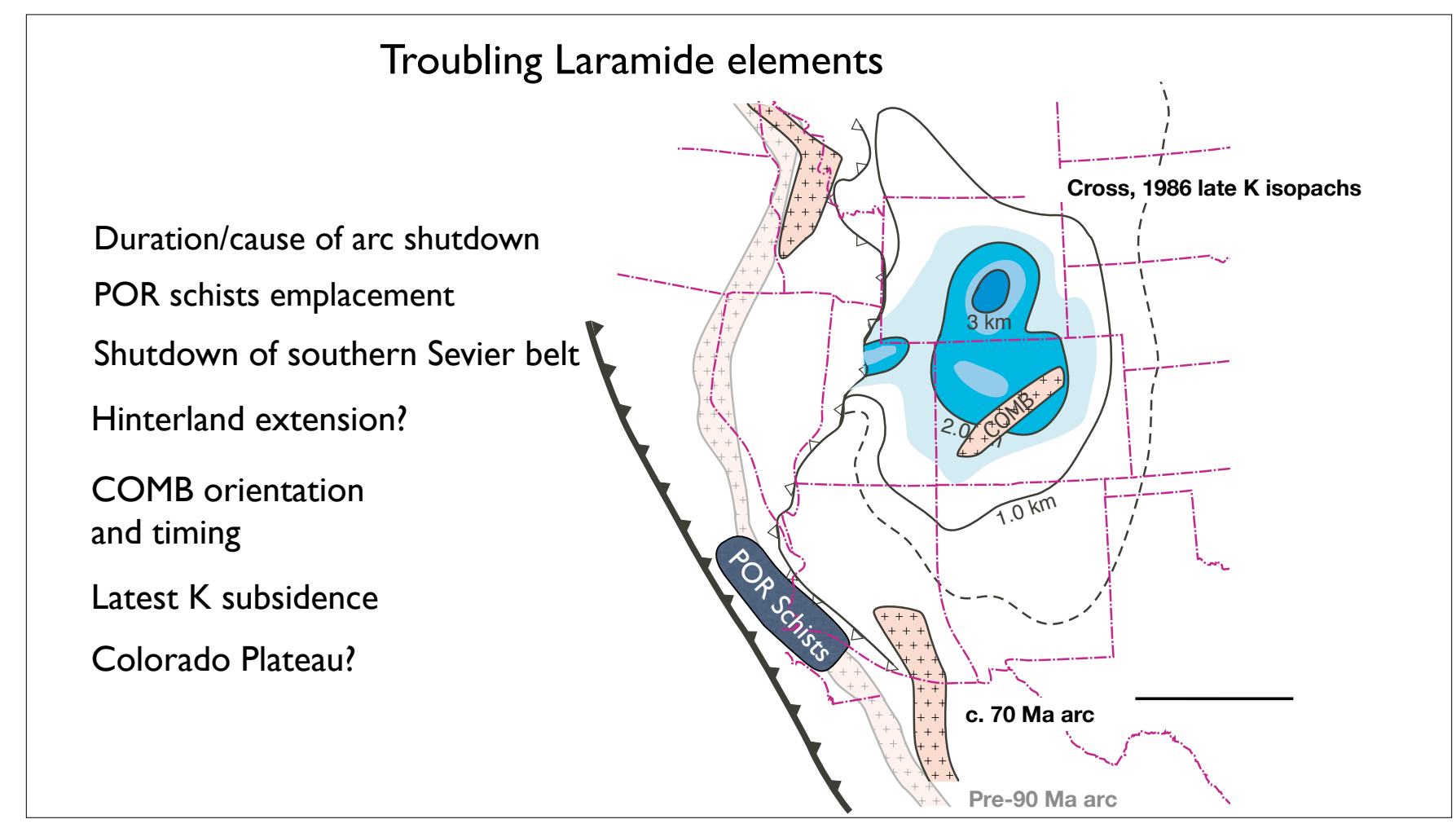

Much of the literature explains this with a subducted oceanic plateau. Will focus on the first four here. POR = Pelona, Orocopia and Rand schists. COMB is Colorado mineral belt magmatism. 


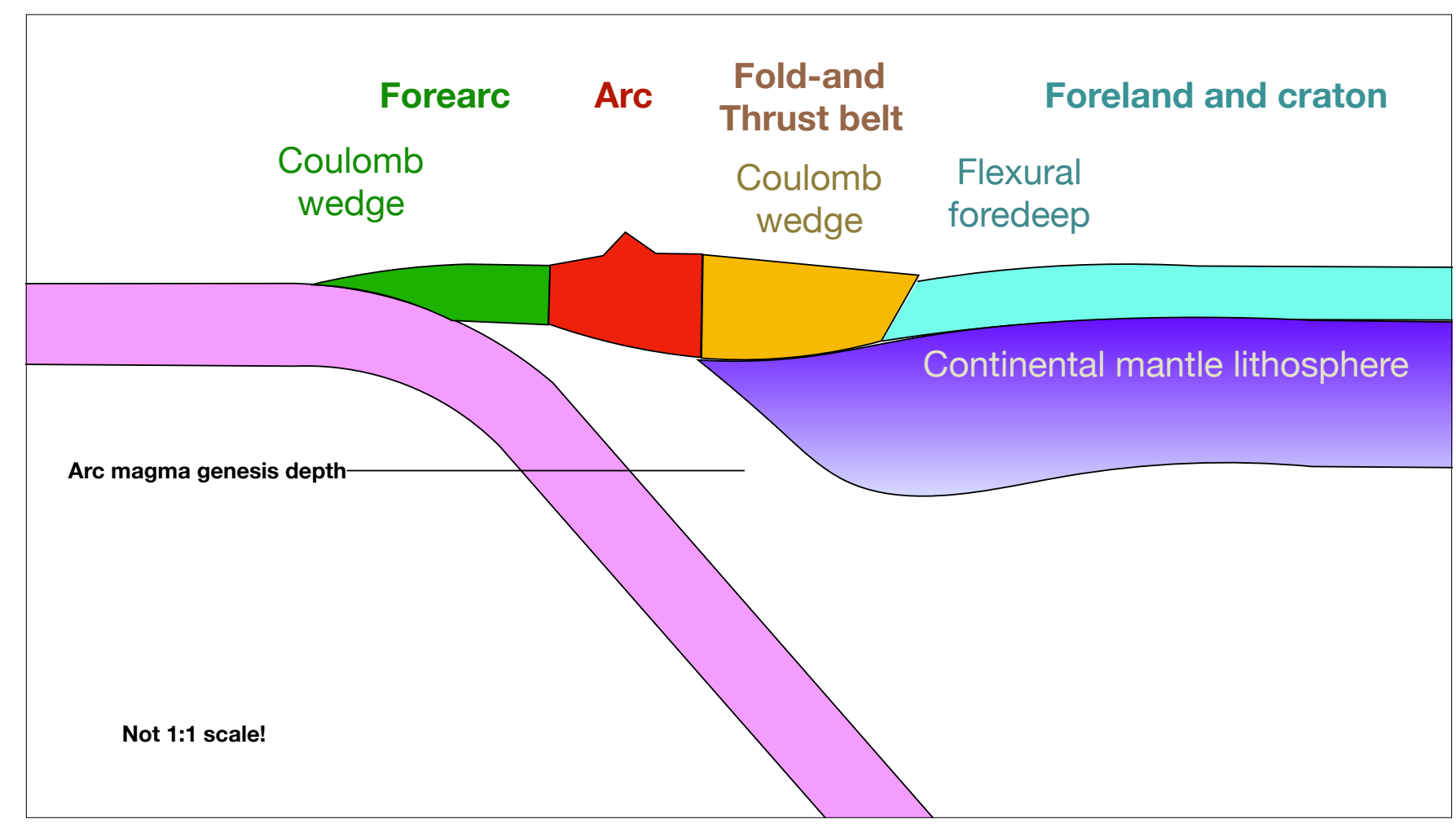

A key to cartoons that follow. We'll assume that tilting the forearc and fold-and-thrust (retroarc) belt will change behavior as suggested by Coulomb wedge theory. 


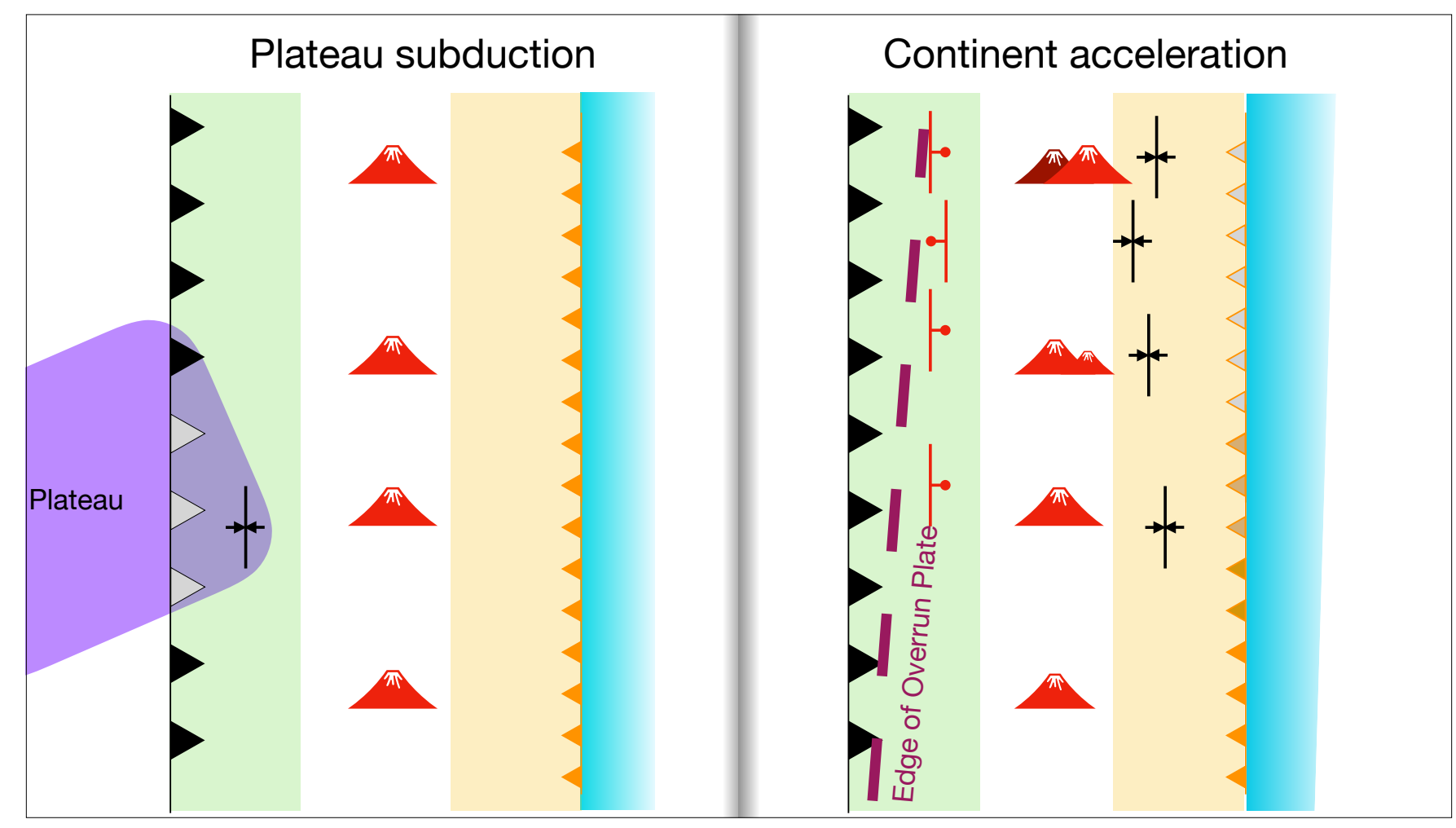

A map view of how things change as a plateau enters the subduction zone (left) and the continent accelerates over a subduction zone (right). On the right, the upper plate is pivoting on a point just below the image. Syncline symbols schematically represent shortening, normal fault (ball on barb) symbols extension. Red volcanos are active, black/orange triangles represent 'normal' thrusting, grayed out triangles slowed or absent thrusting, red triangles accelerated thrusting. 


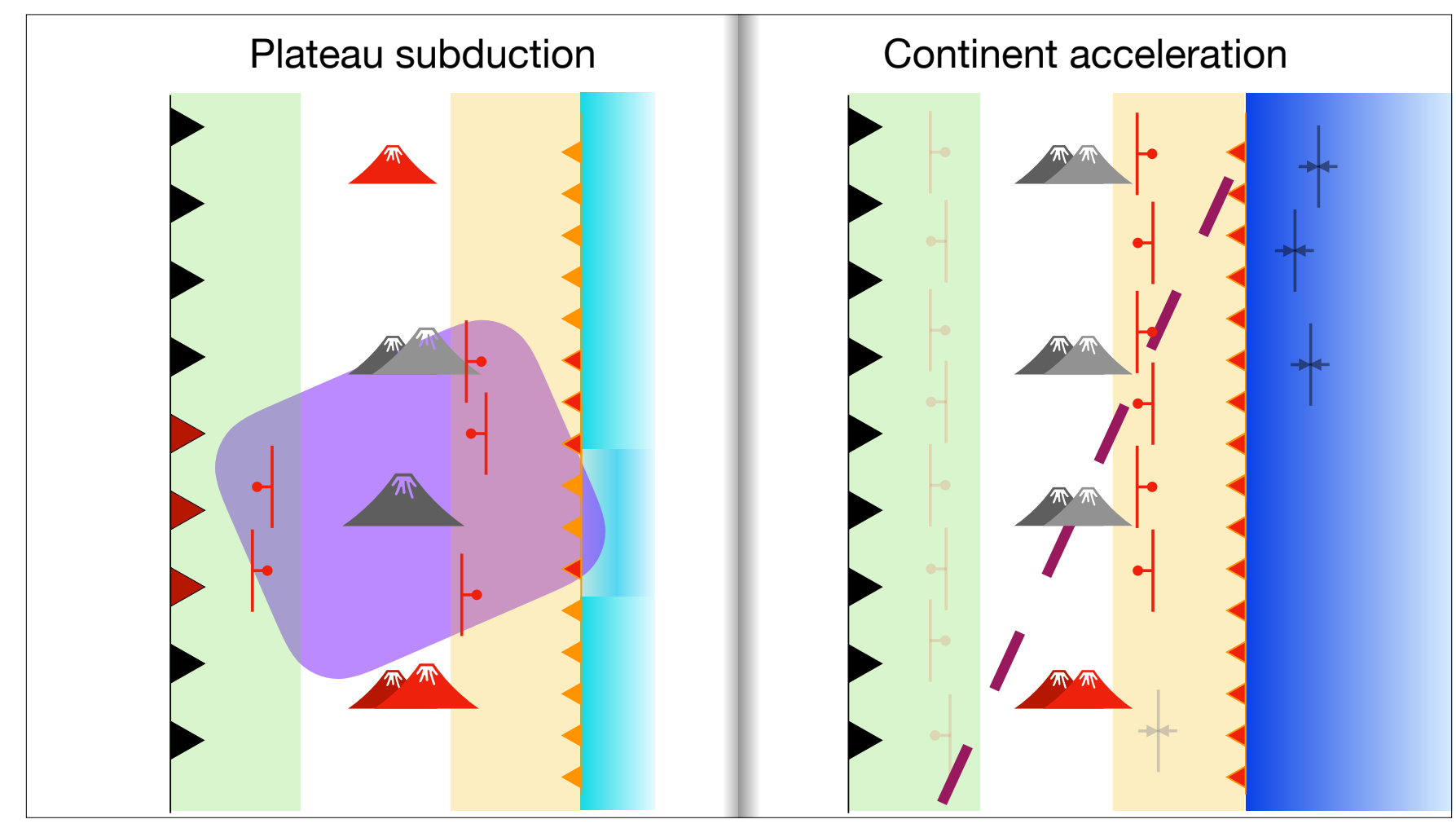

Well along in subduction/overriding. Note in the continental acceleration diagram that the arc is presumed to have a limited ability to migrate to the right. 


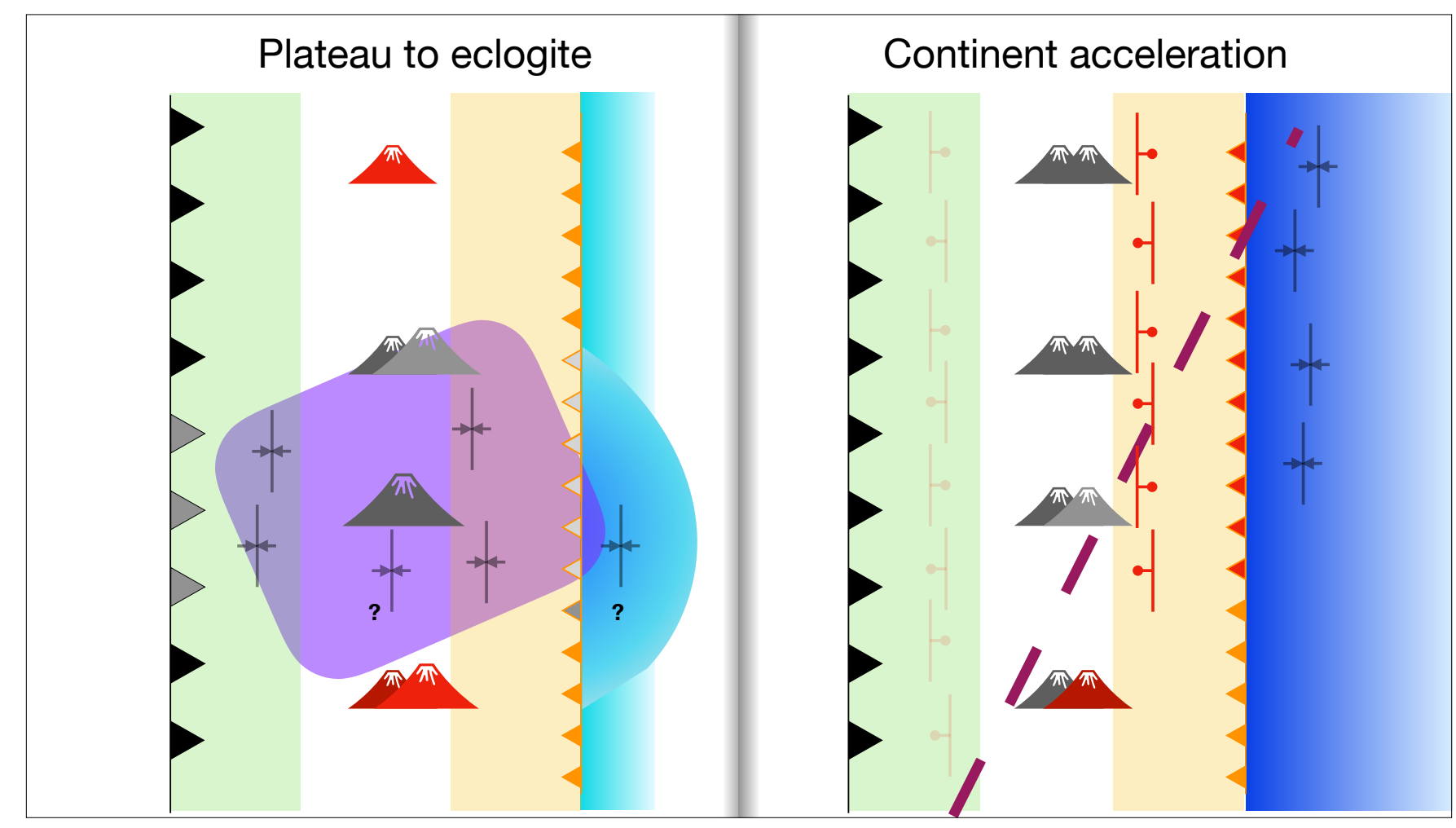

Once the plateau converts to eclogite, stresses reverse in the upper plate as long as the plateau is coupled to the surface. 


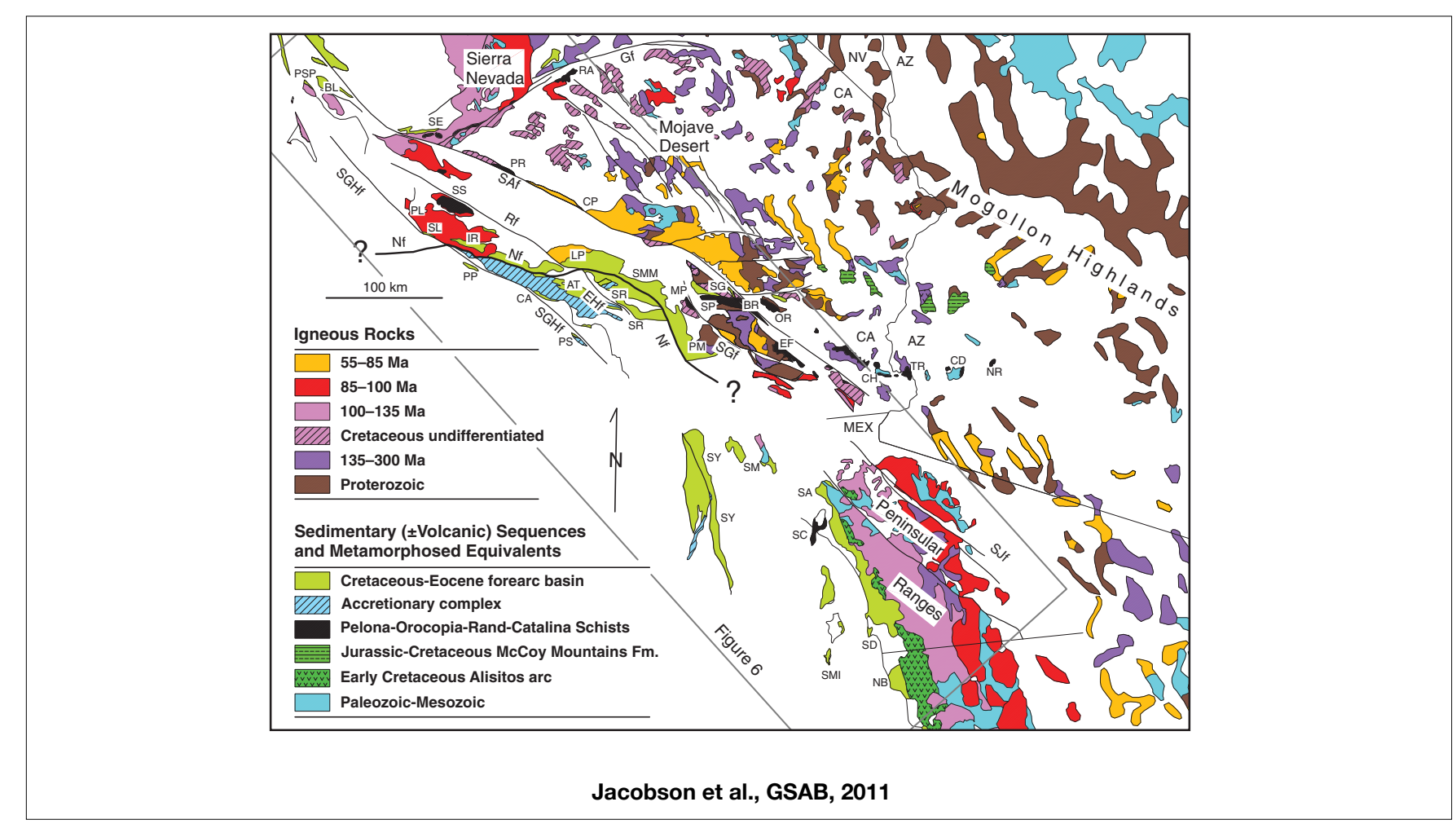

First up, what about the evolution of the arc? Figure is reconstructed for Neogene strike-slip west of SAF, nothing to east. 


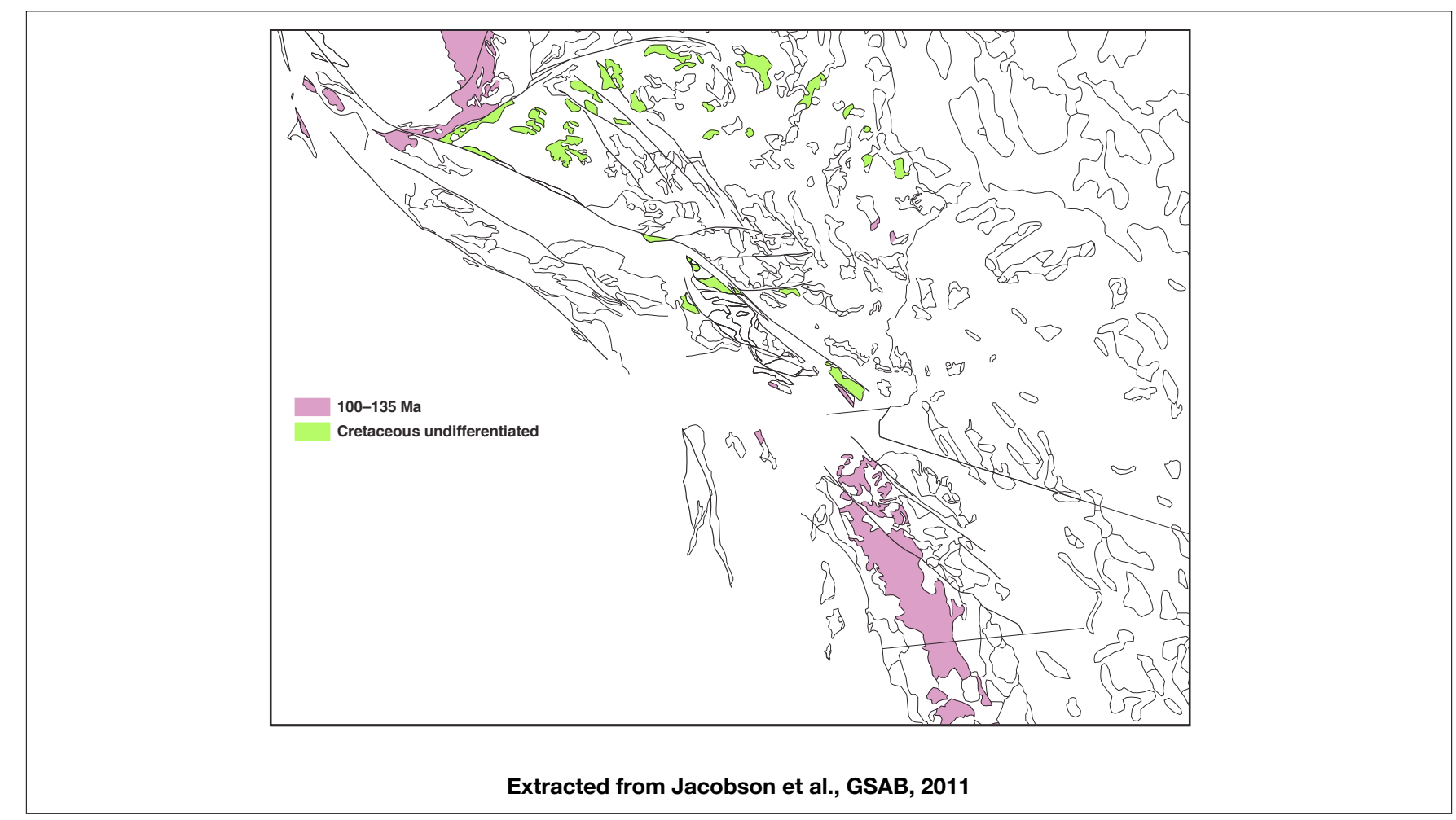

Start with the older magmatism...

(Others have noted that some stuff W of SAF should be farther south) 


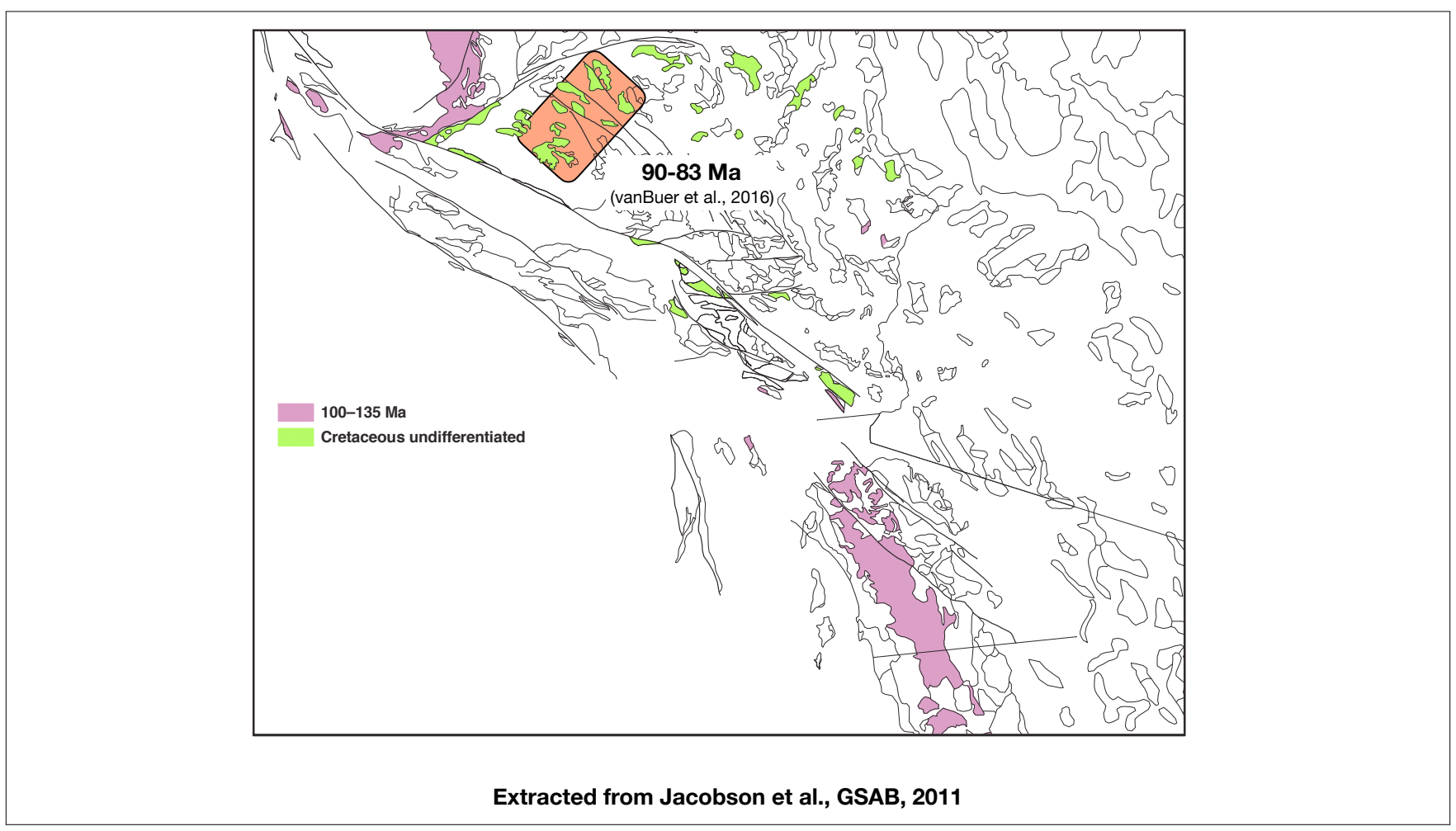

noting that some undifferentiated stuff is in the 90-83 Ma range 


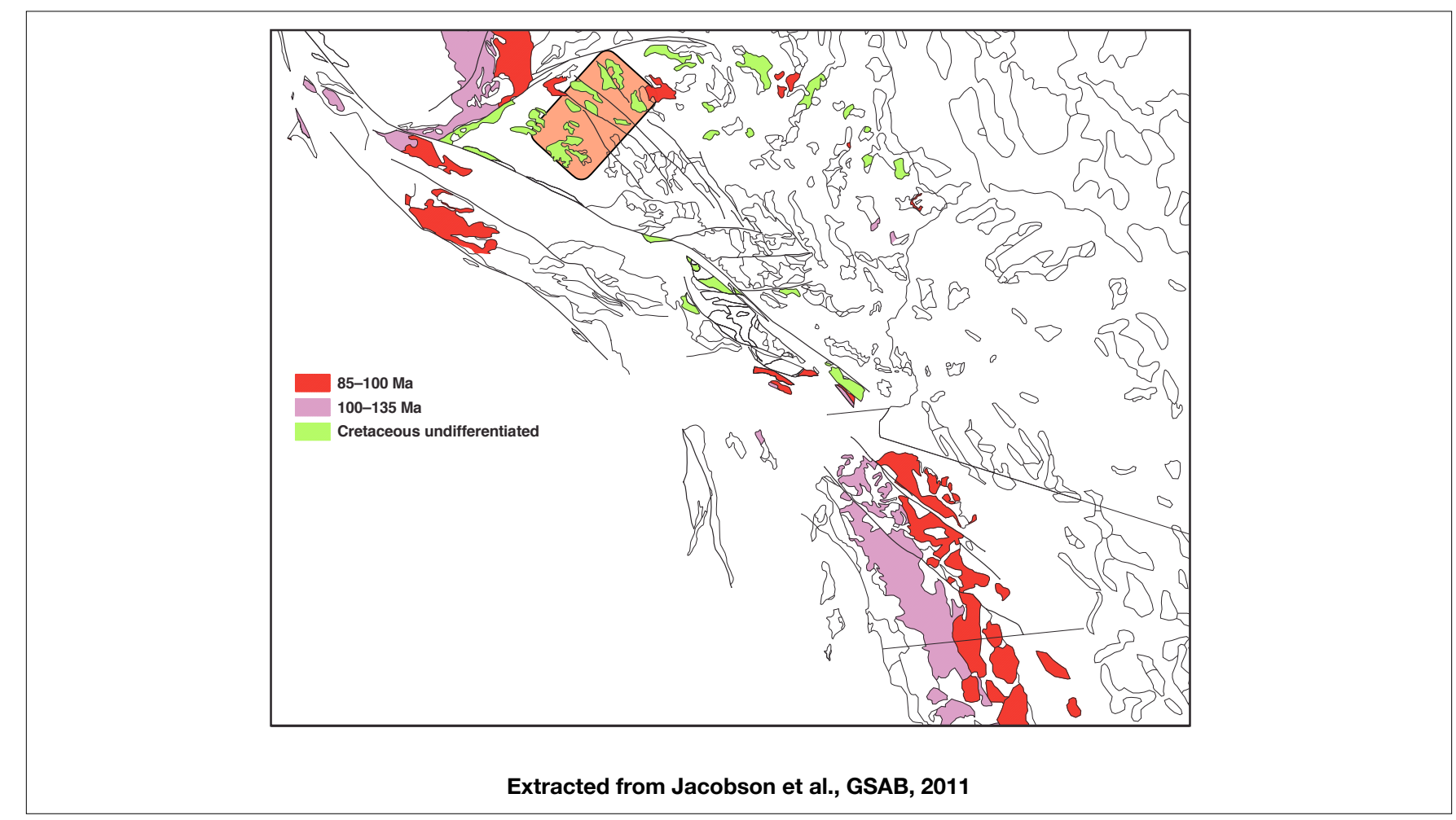

Add in 85-100 ... 


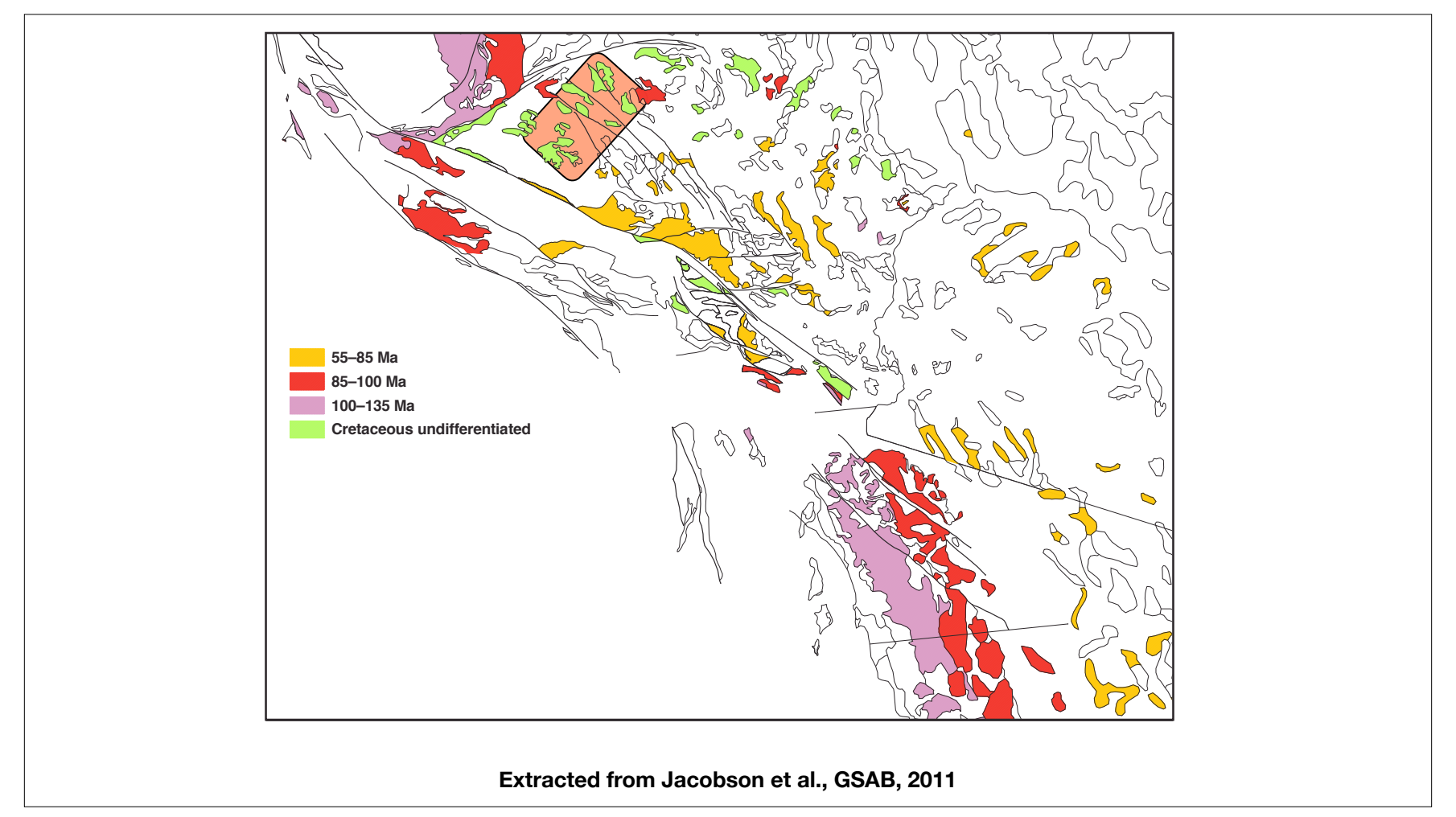

....and finally 55-85, which is mainly 2-85 in California. Clearly see the west-to-east migration to the north and south, but Mojave a mess. Disruption of pattern to $\mathrm{N}$ and $\mathrm{S}$ long noted, but note too this isn't simply a clean movement to west (though there is one tiny piece in Whipples with the proper west-east migration). Also, a *lot* of $72-85$ Ma stuff in the Mojave.... 


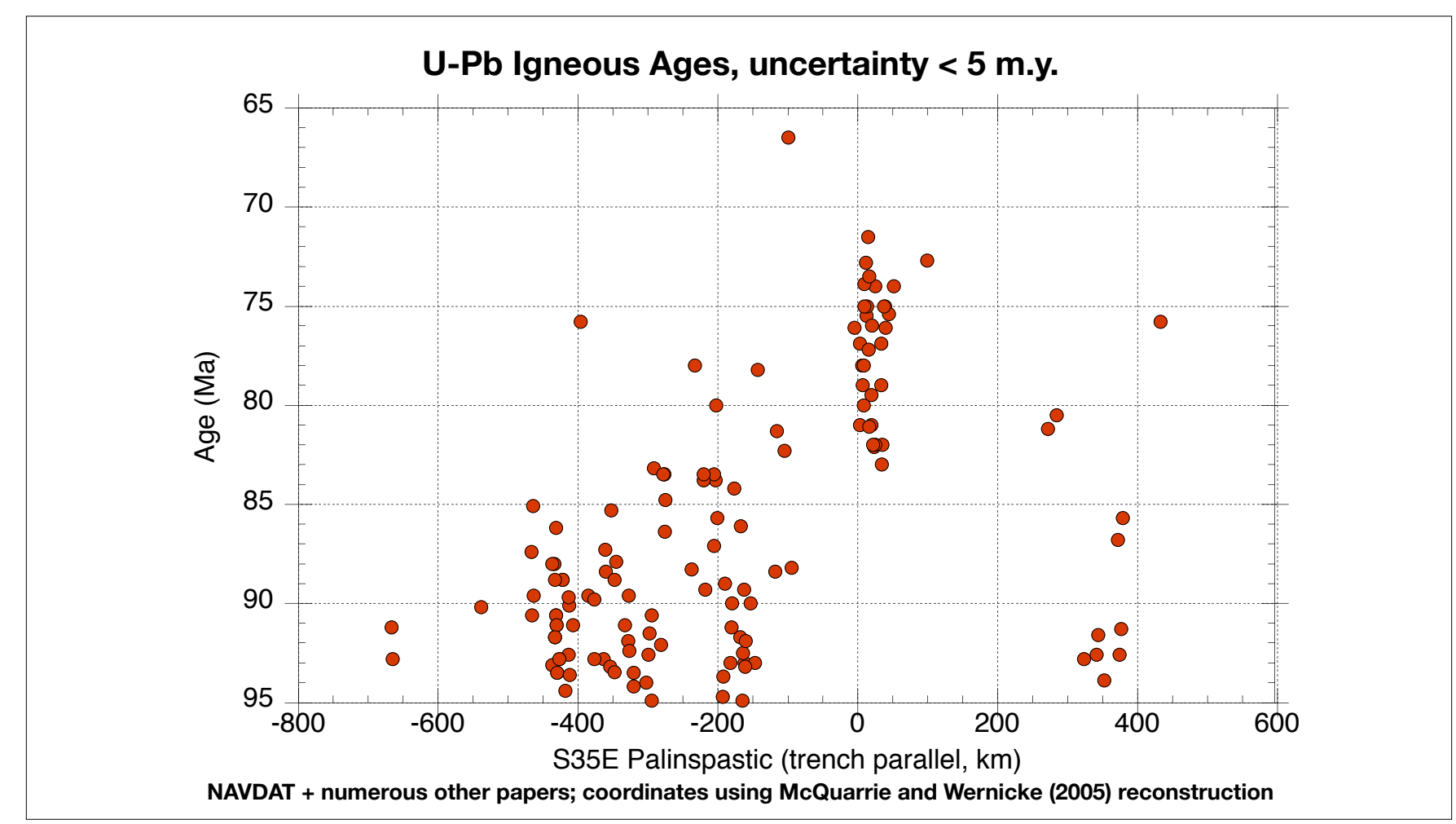

Projecting U-Pb ages onto a profile parallel to plate margin, this time from McQuarrie and Wernicke palinspastic reconstruction that includes deformation to the east. Sierra to the left, Peninsular Ranges to the right, zero in the Mojave. 


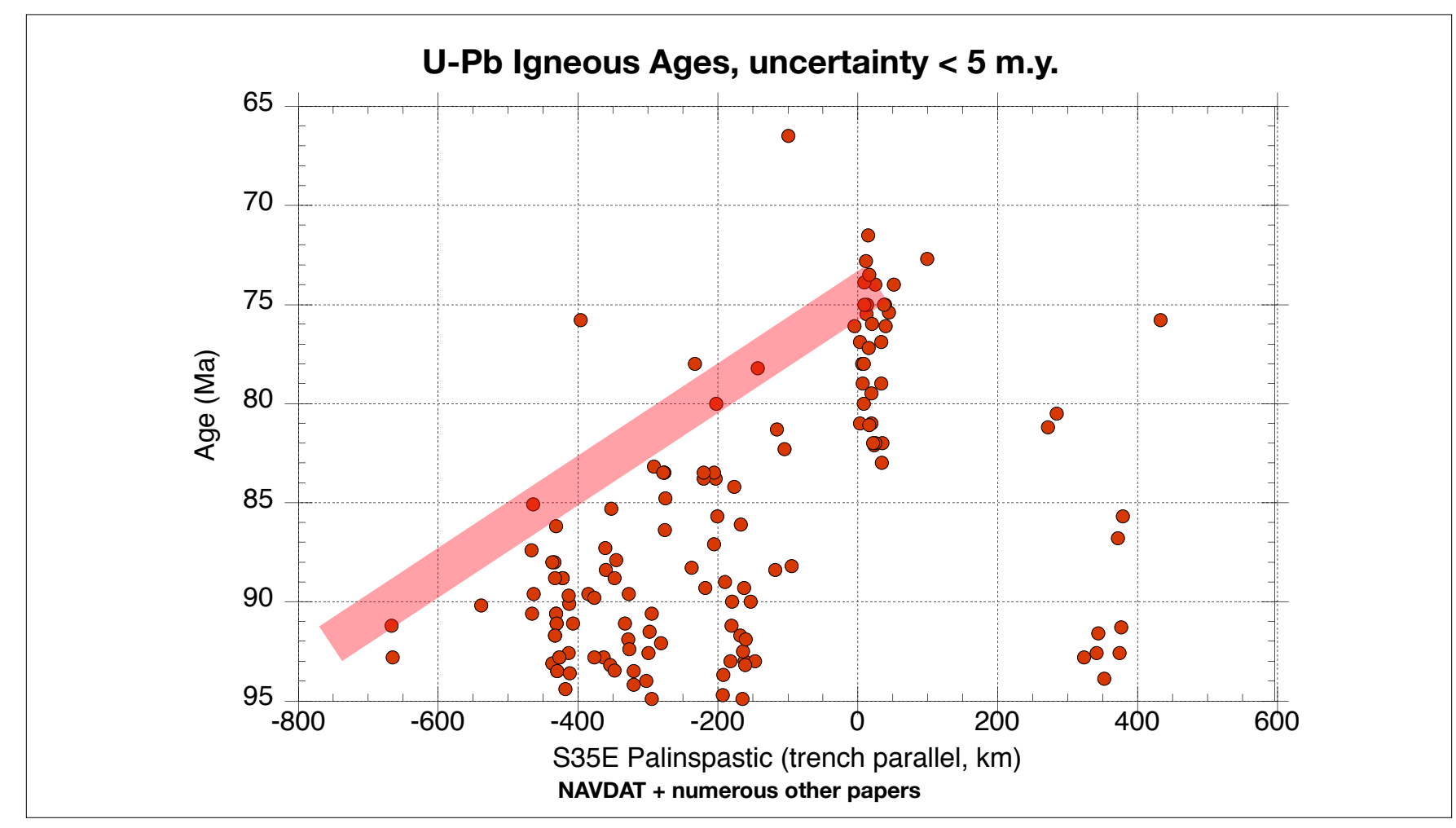

Two points: Seems arc shut down from the north. Also, quite the collection of points in 83-72 Ma range in the Mojave. These are also within $\sim 200 \mathrm{~km}$ of the plate edge. (The gap in the Mojave has been pointed out elsewhere; whether this reflects an inadequate restoration of material now west of the San Andreas or that this part of the arc has been overthrust is not something discussed here). 


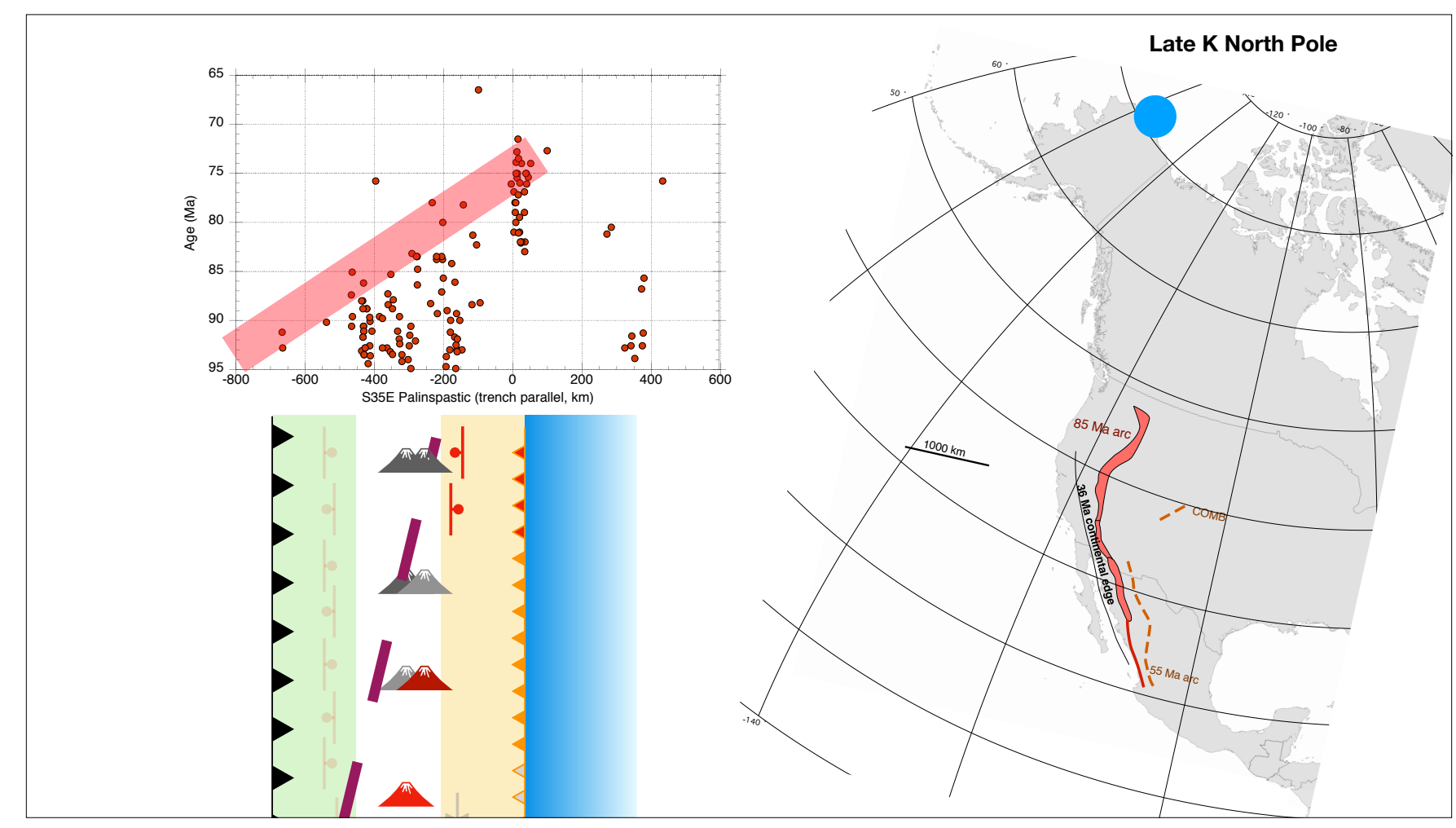

Why the north to south shutoff? Maybe because North America was rotating about a point in central Mexico, which moved the North Pole from near Pt. Barrow to near its modern position. 


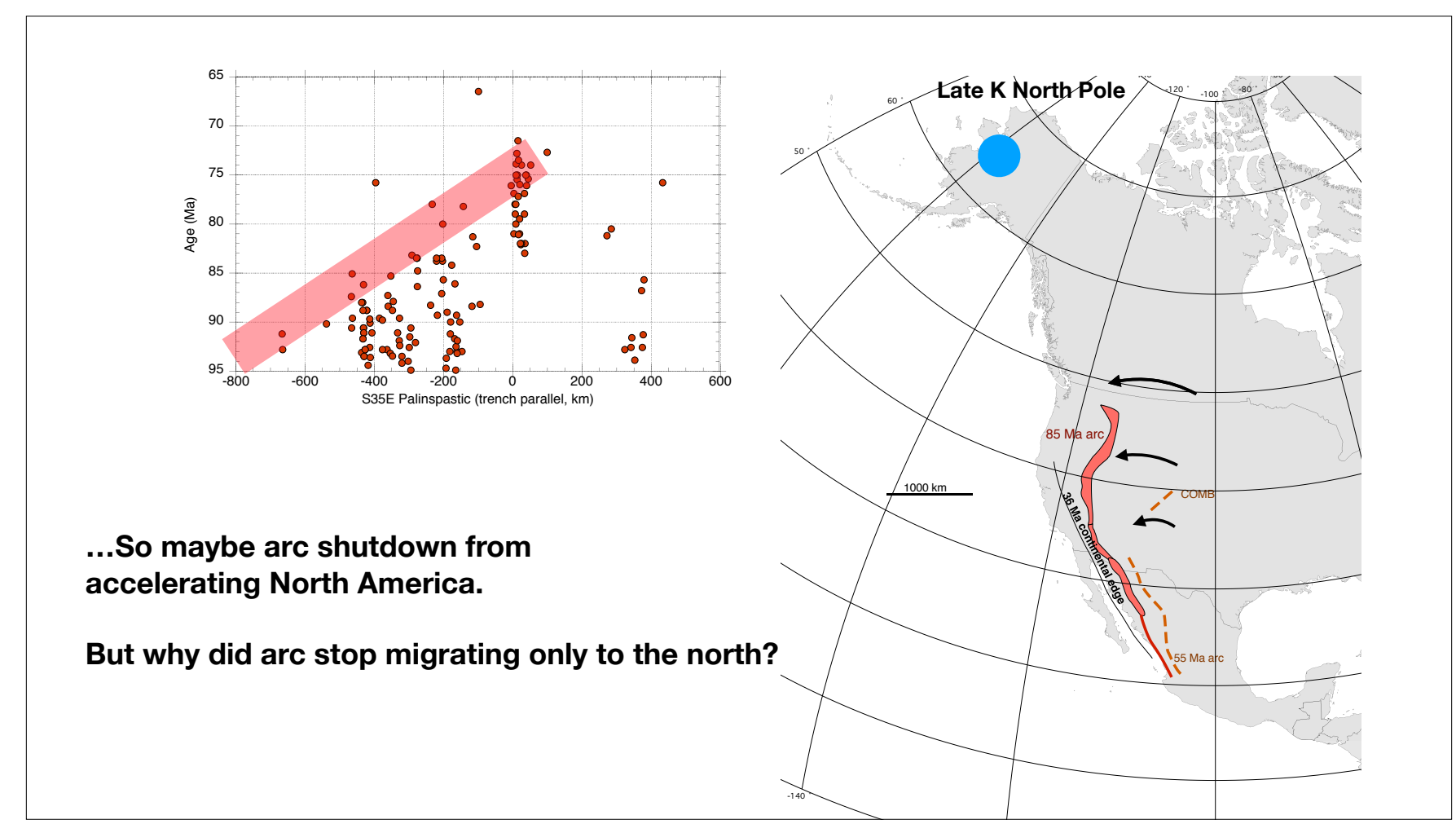




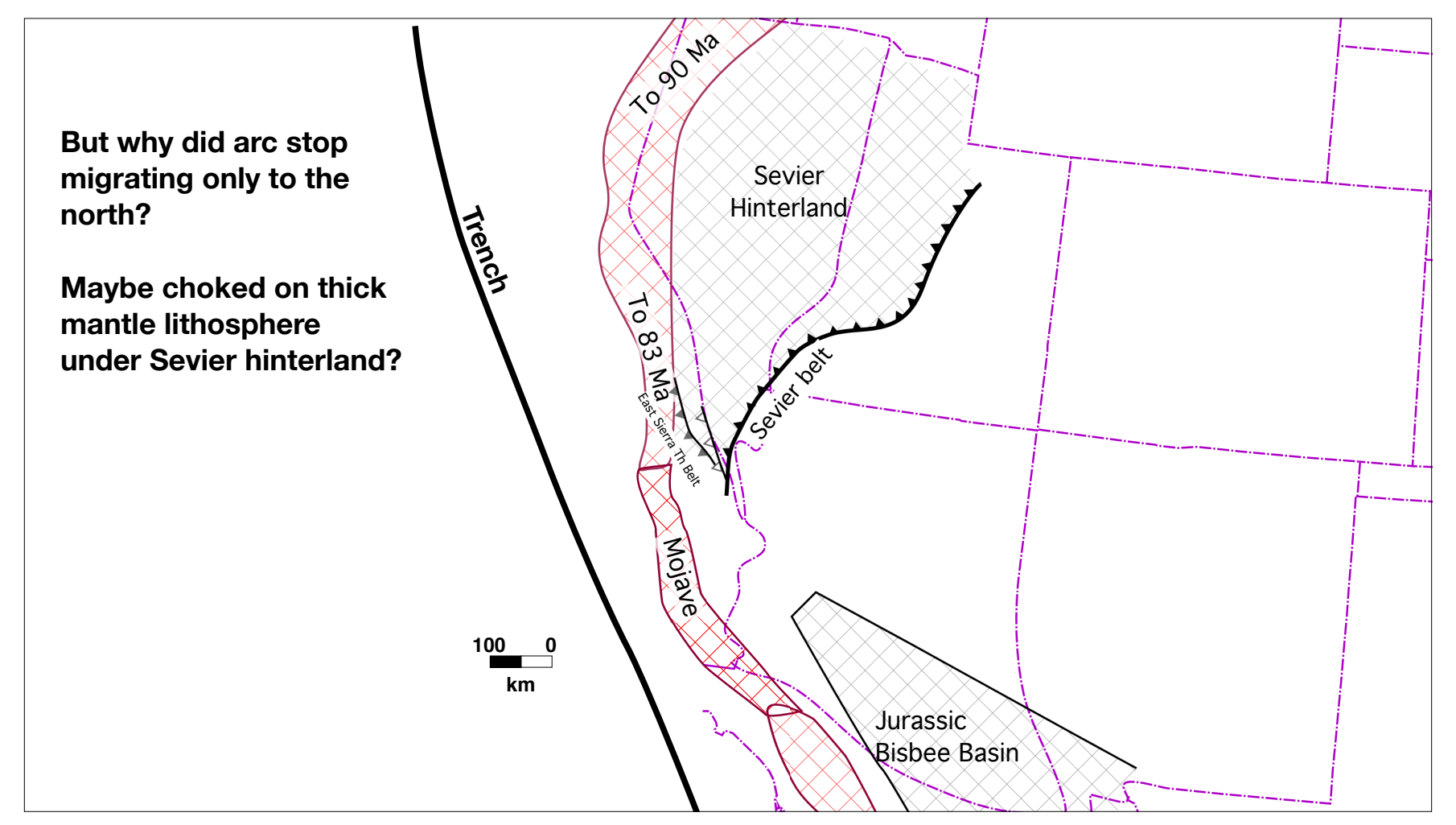

This is speculative, of course, though kind of aligned with recent Axen et al. paper kind of suggesting something like this. Note that to south, no such thick lithosphere in wake of Bisbee Basin, so arc continues to migrate. 


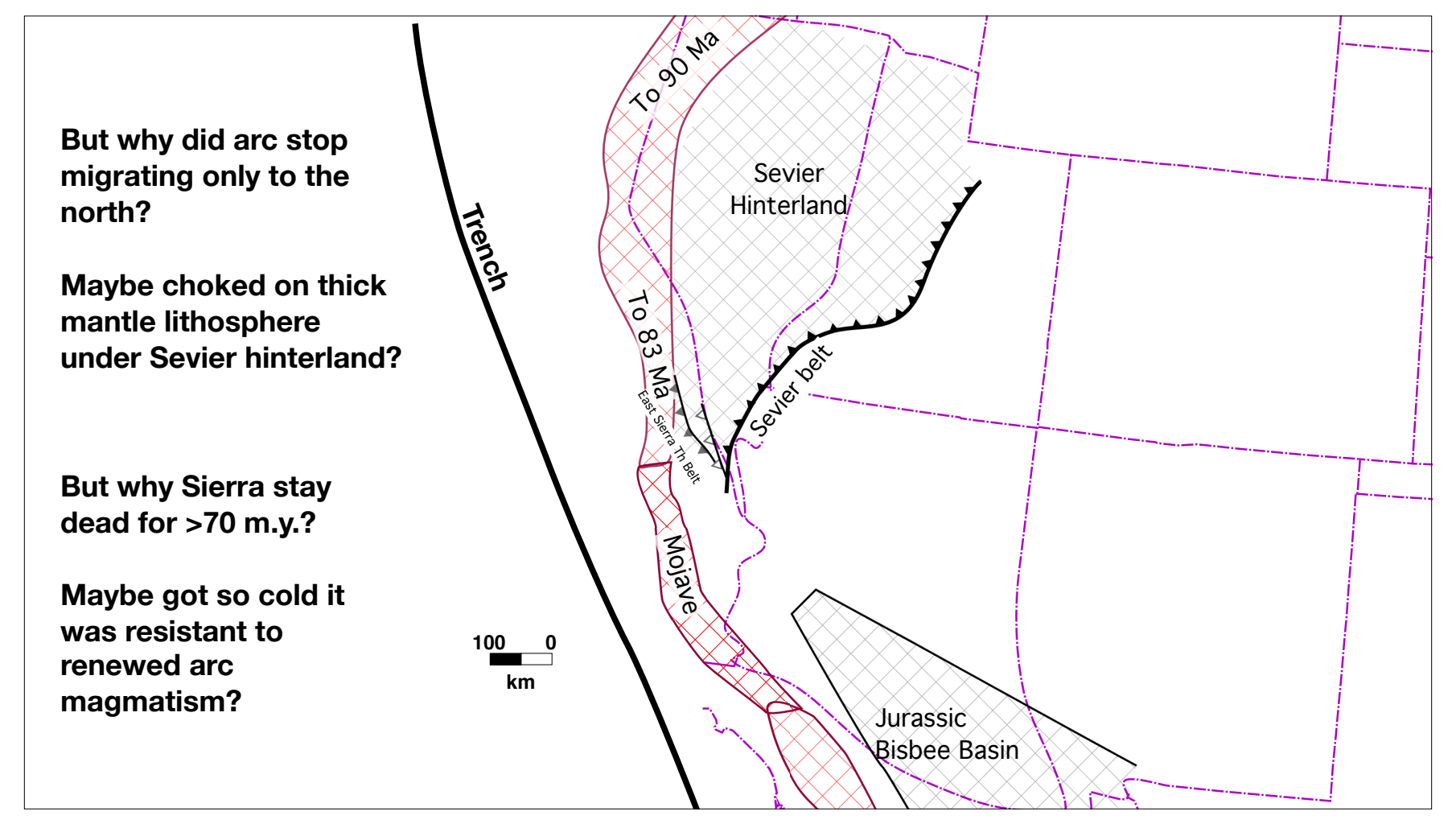

Might note there are peraluminous granites that maybe have some mantle contribution. Second explanation requires long lived shallow subduction. Would suggest that some numerical modeling would help here. 


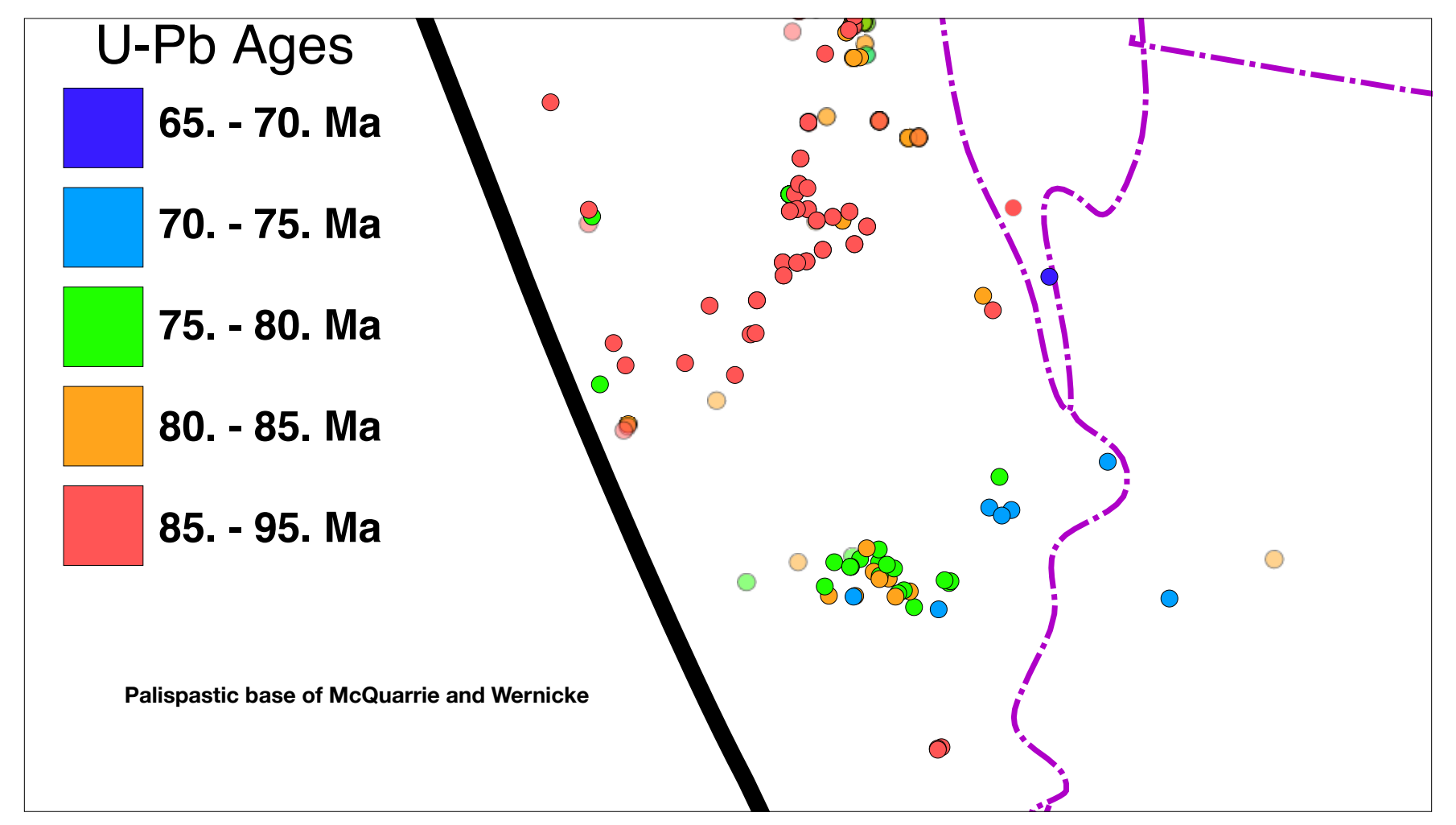

Note lack of migration of ages in Mojave-is this bad restoration? Or is magmatism behaving differently? And just what are those $72-83$ Ma magmas, many of which are metaluminous and look like arc rocks? 


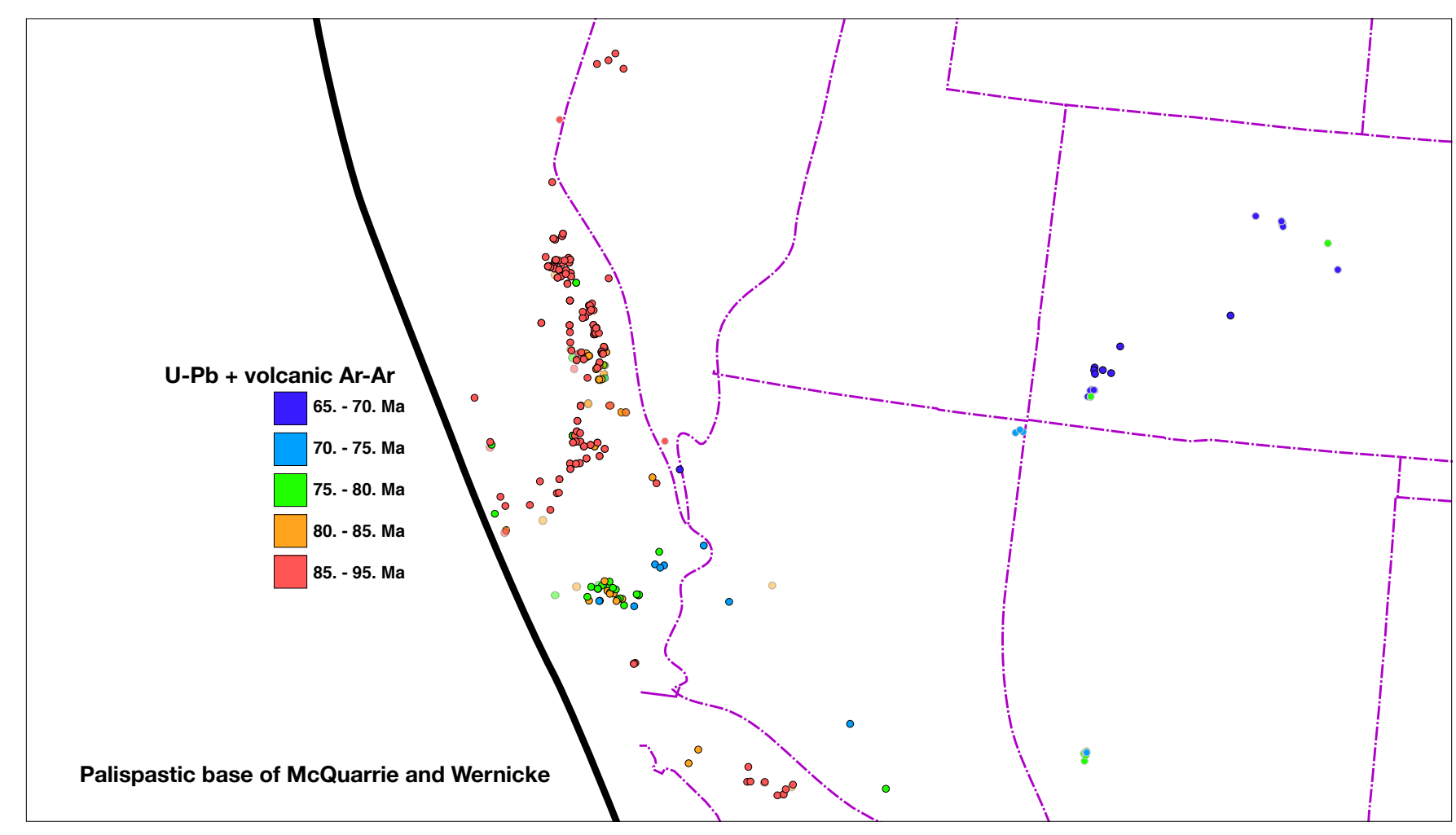

A curiosity is that nearly coeval volcanics and intrusives are seen in Colorado on this northeast trend, nearly parallel to inferred Farallon-North America relative motion. 


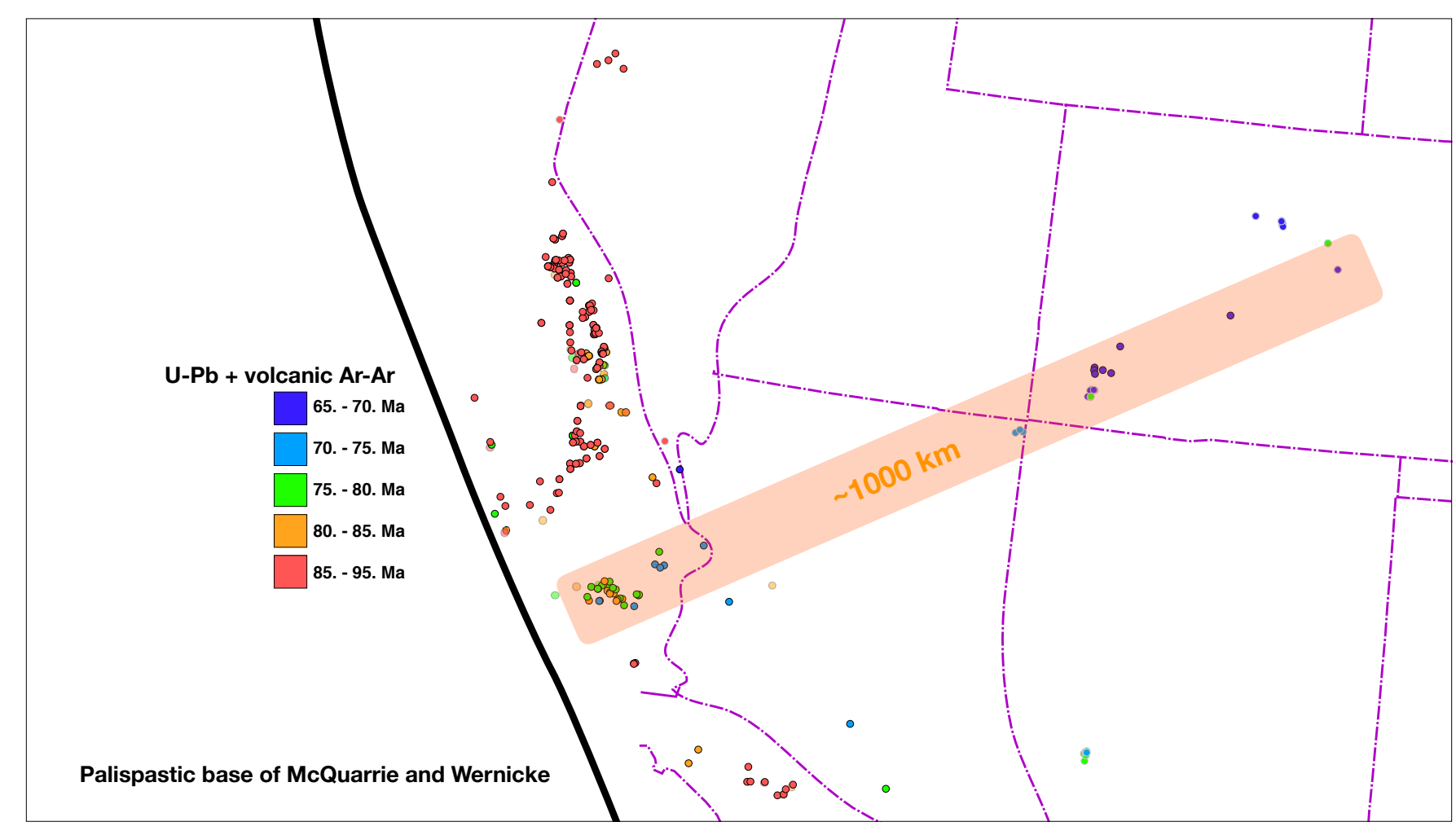

So this is a puzzle-what does it mean? How would this work with subducting a plateau? 


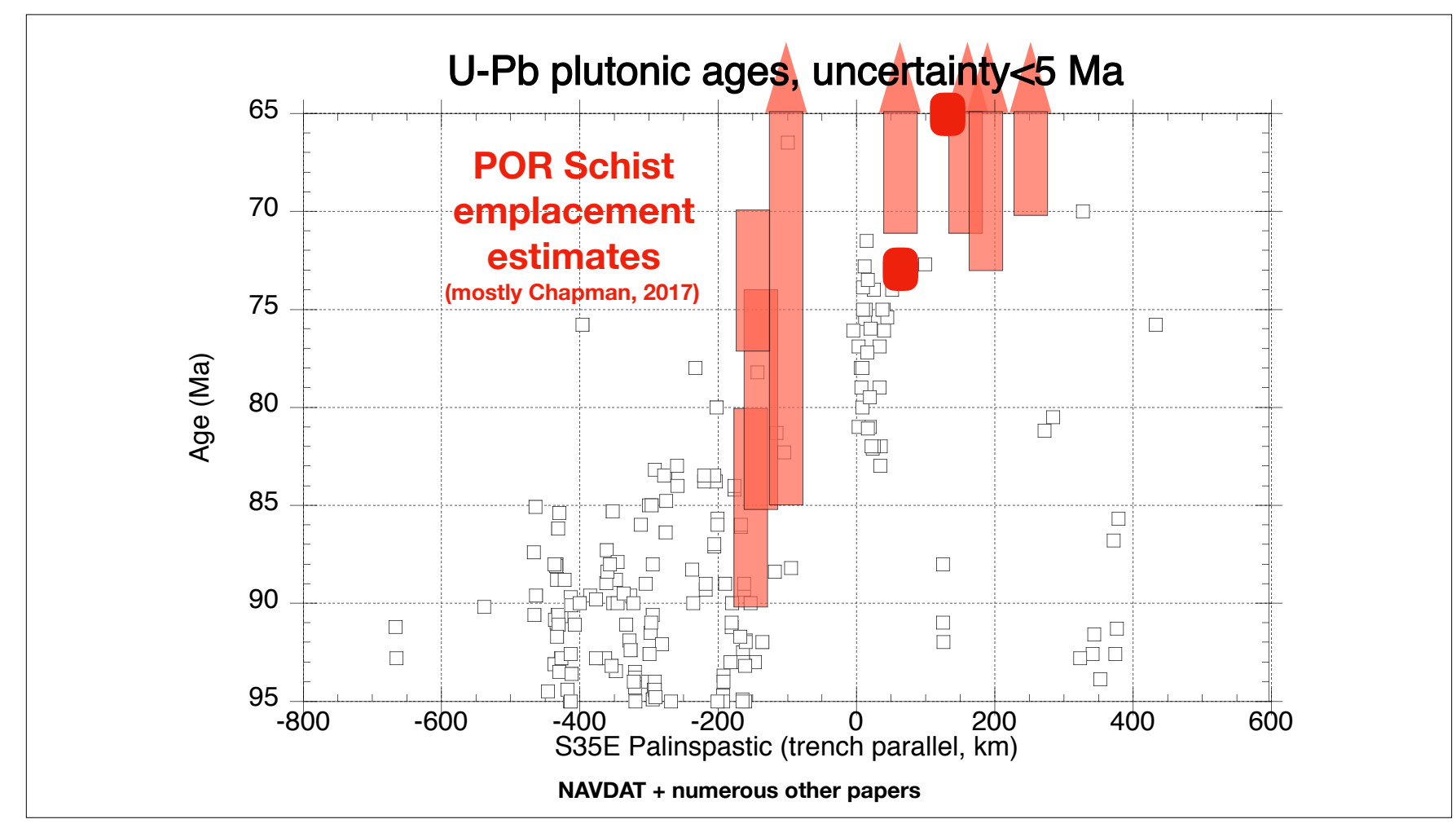

Now the POR schists. Emplacements are red boxes (igneous ages are white boxes). How much of this pattern is real? After all, don't know about any subsequent extension.

What is exceptional here? Why do we get these schists in this area and not others? Heavy red dots are Plomosas (73 Ma, Seymour et al., 2018) and Cemetery Ridge (65 $\mathrm{Ma}$, Jacobson et al., 2017). Note P-O schists come in right as magmatism dies while Rand schists seem to potentially overlap with arc. 


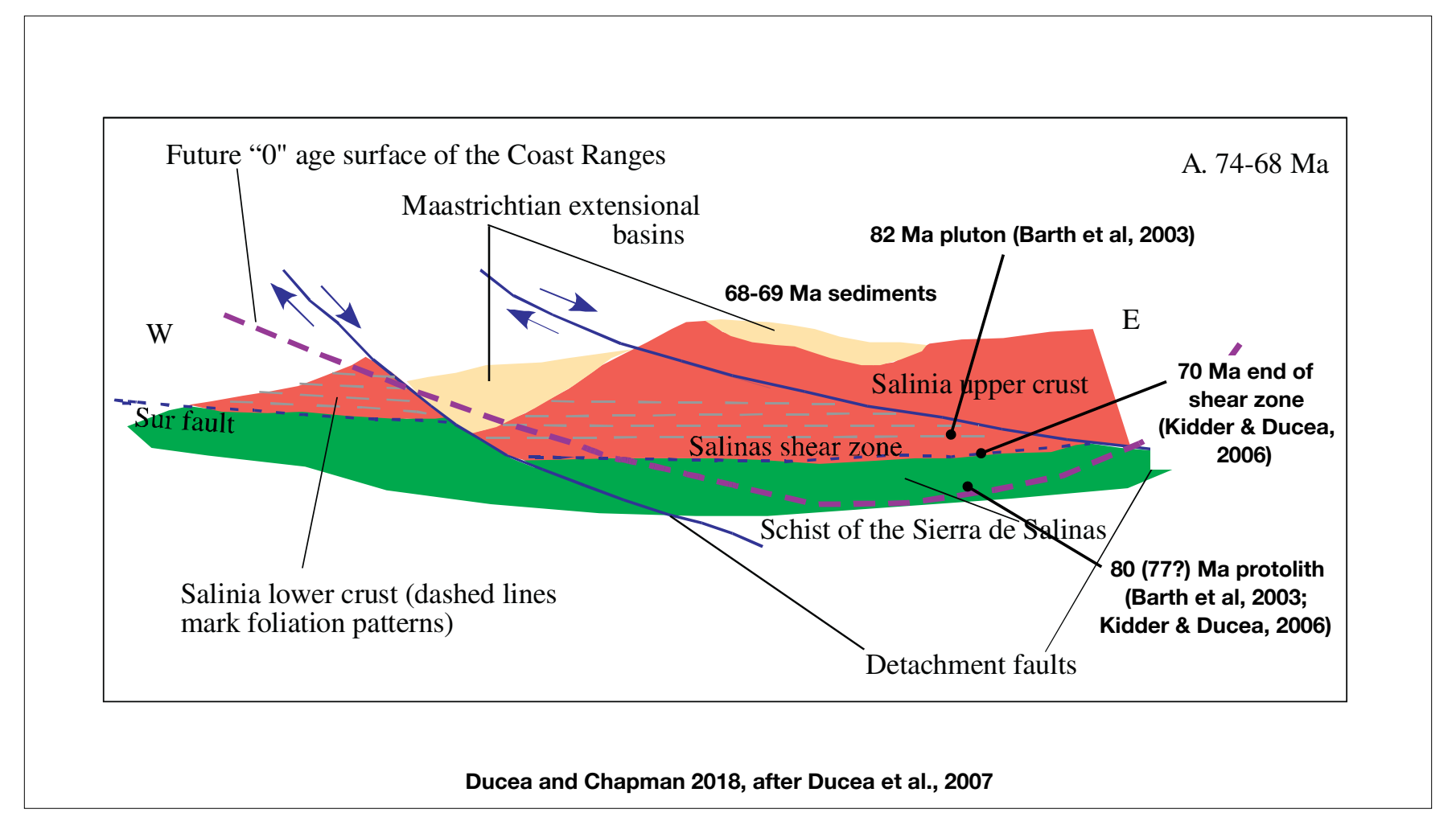

Model of Ducea and Chapman one of several-all of which center on thrusting [so far as I can tell] to get the roots of the arc juxtaposed with the schists. 


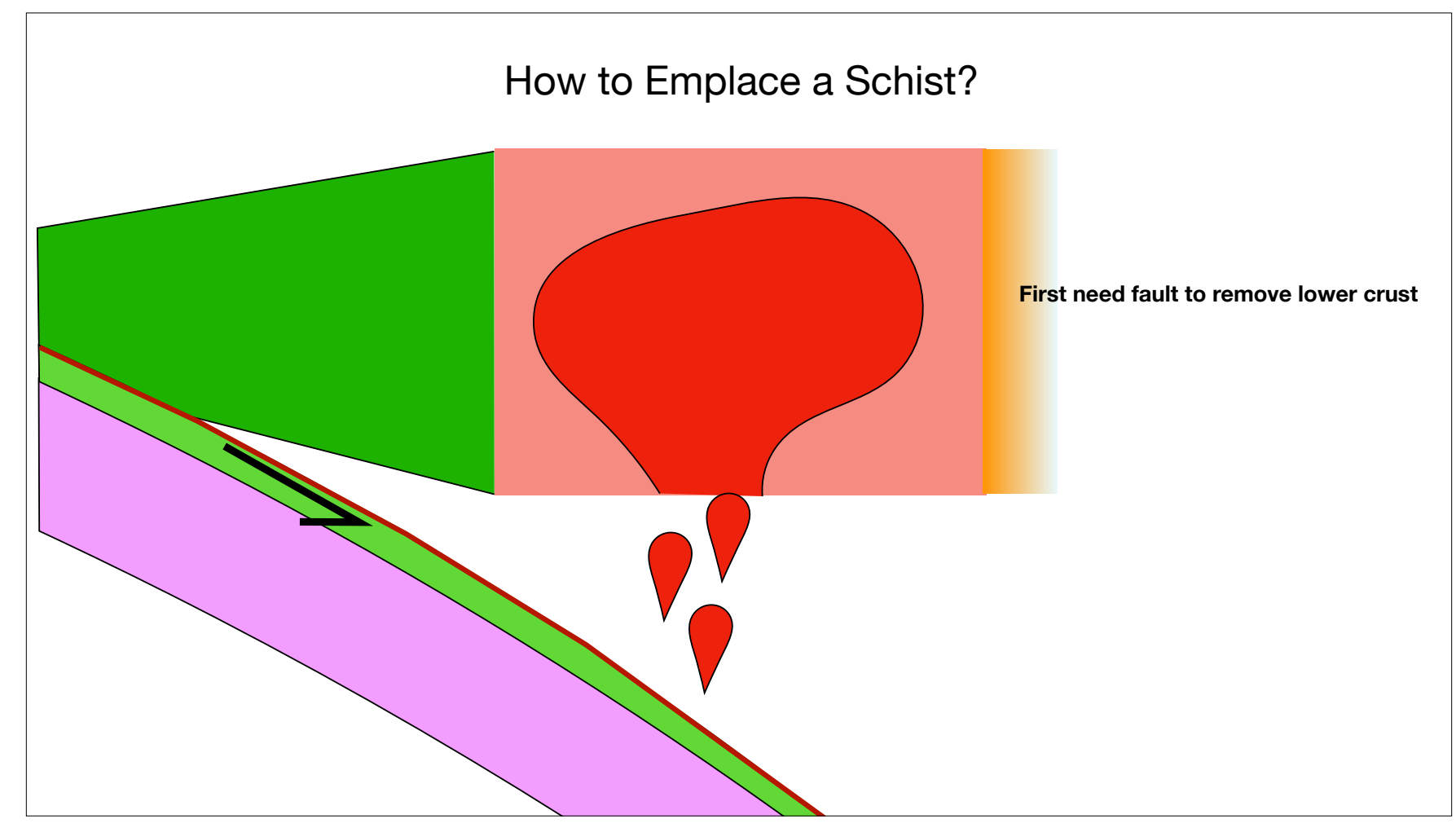

So how would this work? A schematic exploration... 


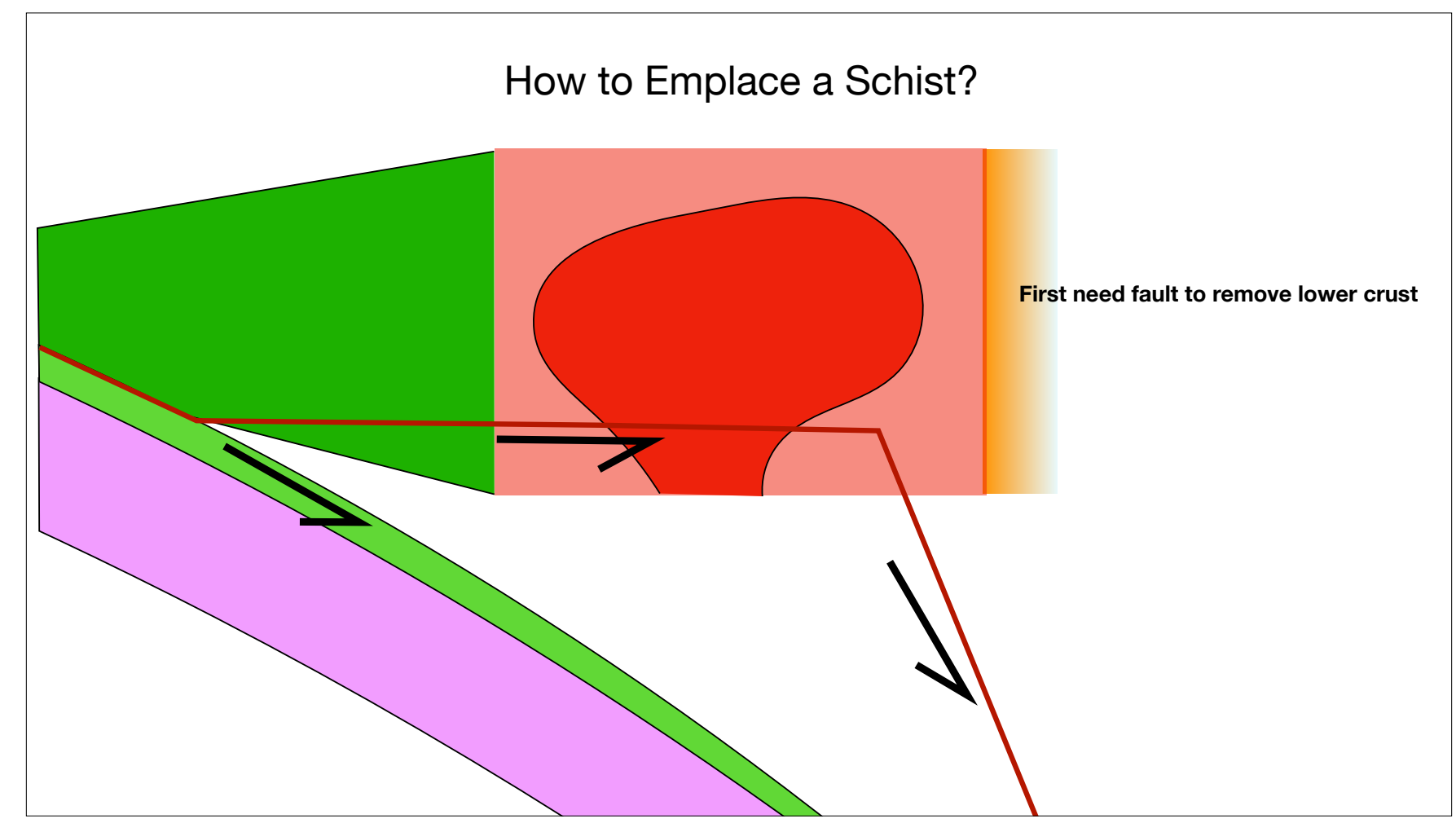

If rising up, need to remove no less than $50 \mathrm{~km}$ of material that was under the arc. Sideways that much or more (dip unlikely more than 45 degrees by this point). Hard to do in under 5 m.y. 


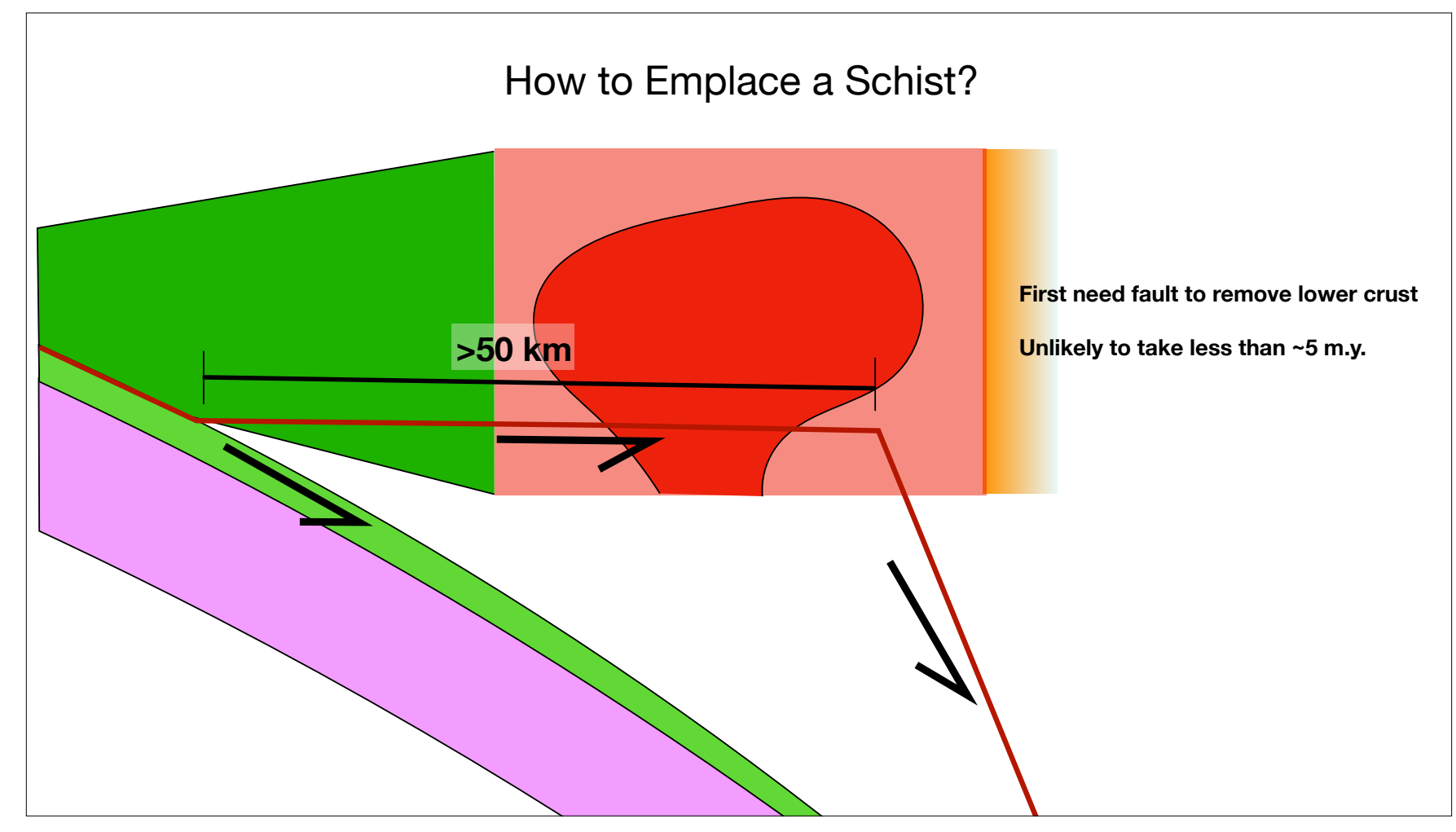

If rising up, need to remove no less than $50 \mathrm{~km}$ of material. Sideways that much or more. Hard to do in under 5 m.y. 


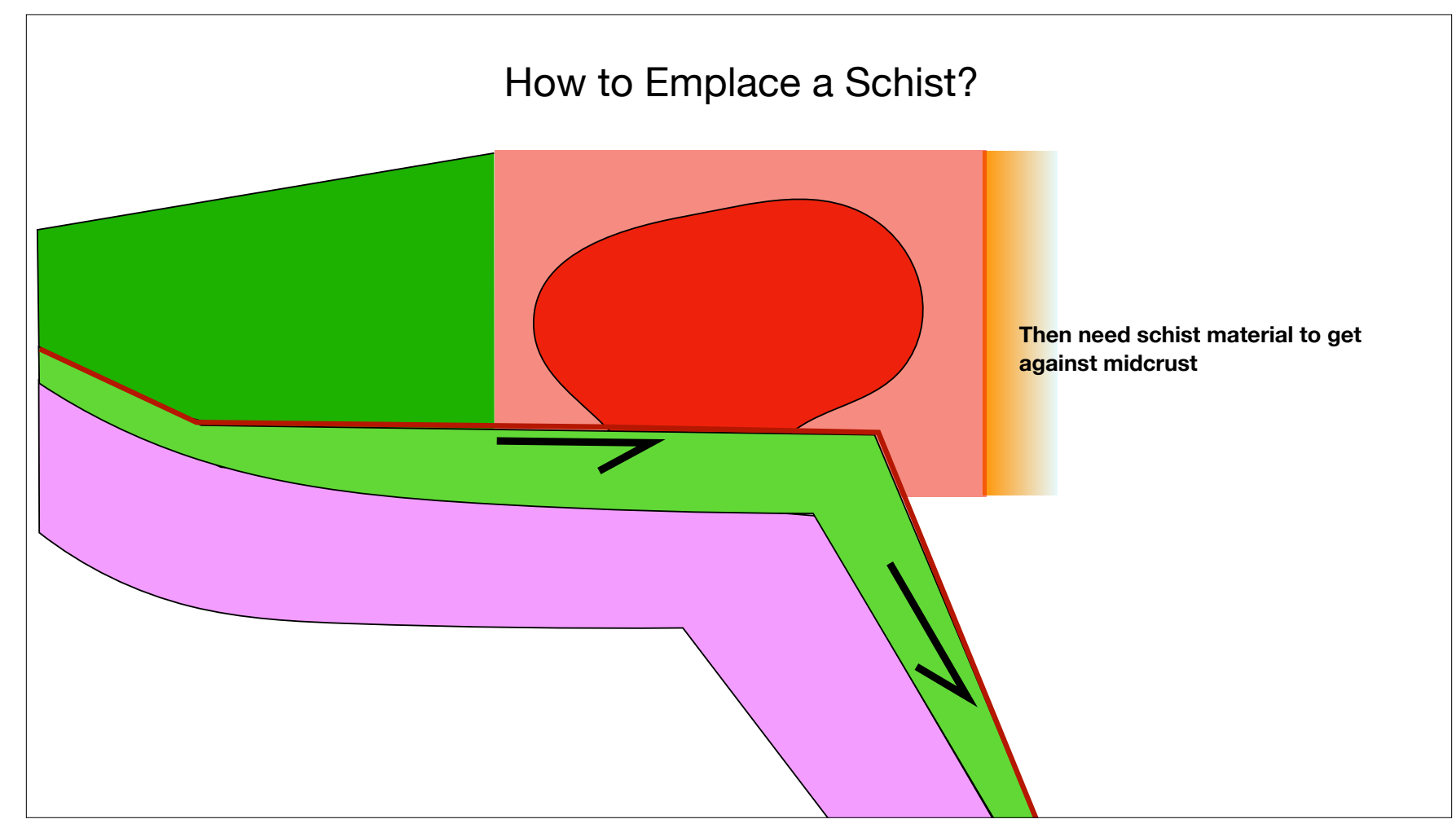

Inverted metamorphic gradient in schists hard to do if schists keep traveling past the pluton. Note that I haven't worried about moving schists down and back up, as is generally inferred. 


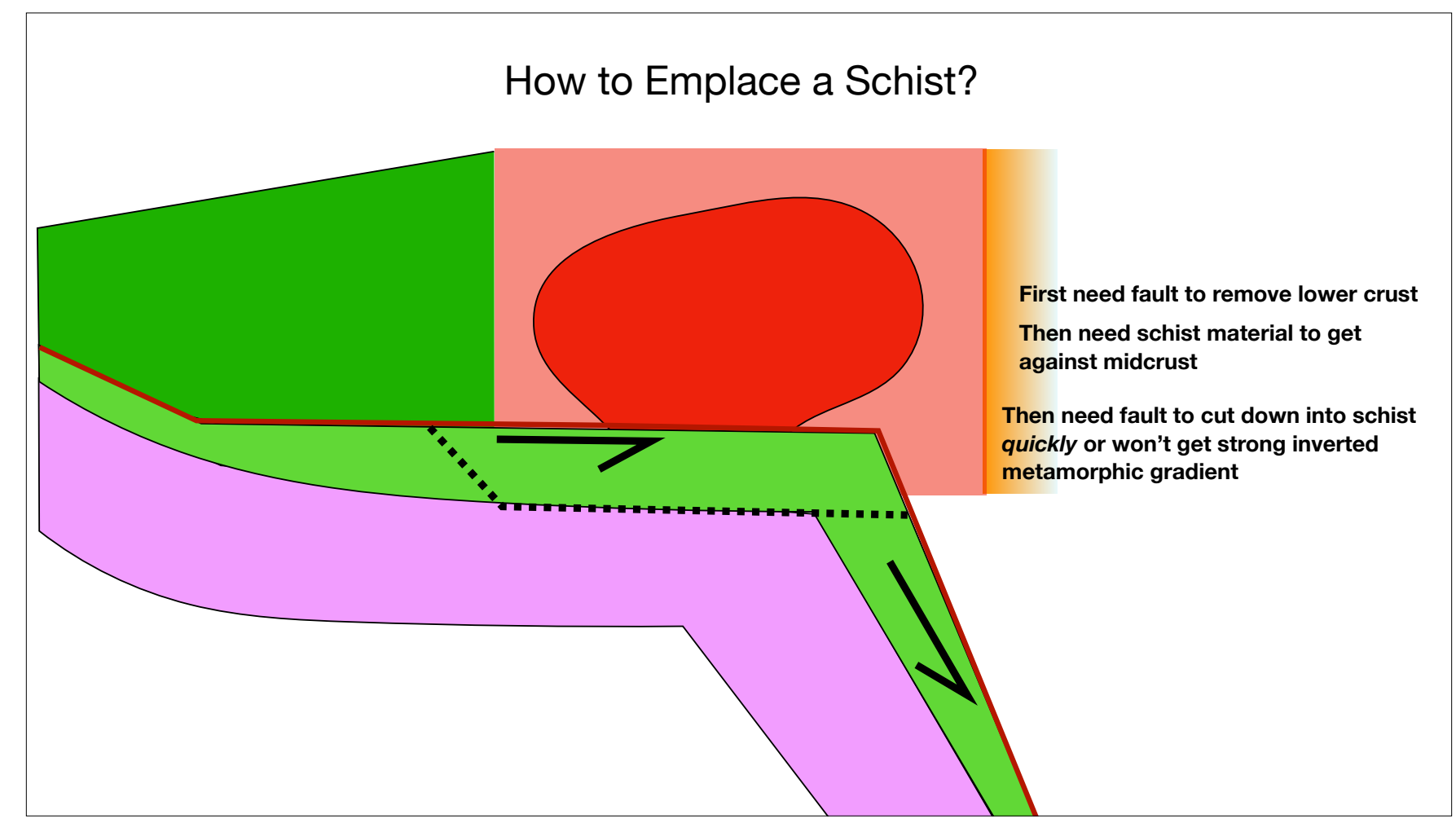

Quick cut downward shortly after thrust cut up. 


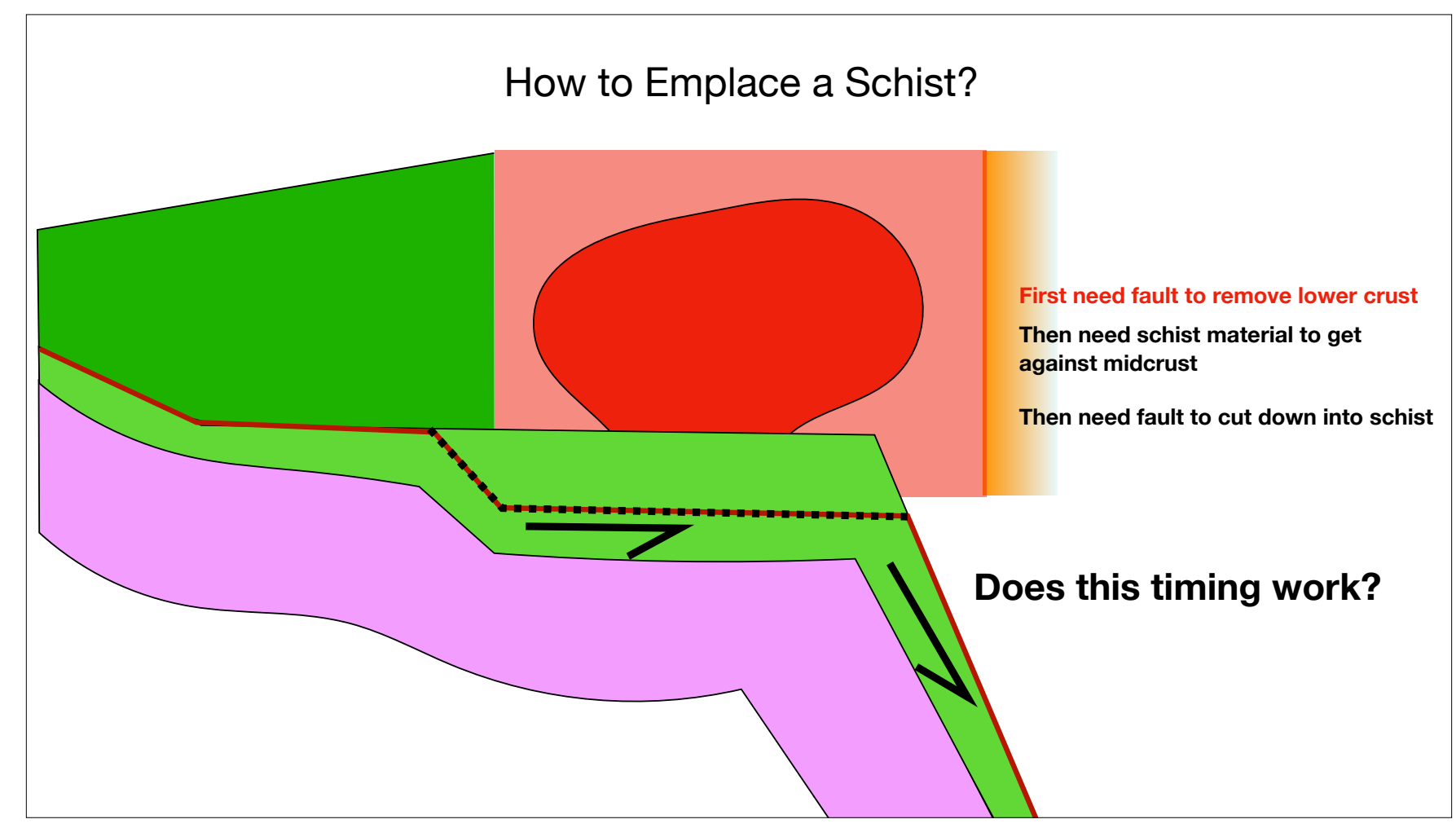

If schist protolith is less than c. 8 m.y. older than cooling pluton, seems like this is very hard to do...and then there is extension right after this to move these rocks higher up ("${ }^{*}$ uch* higher up in case of Salinian schists). 


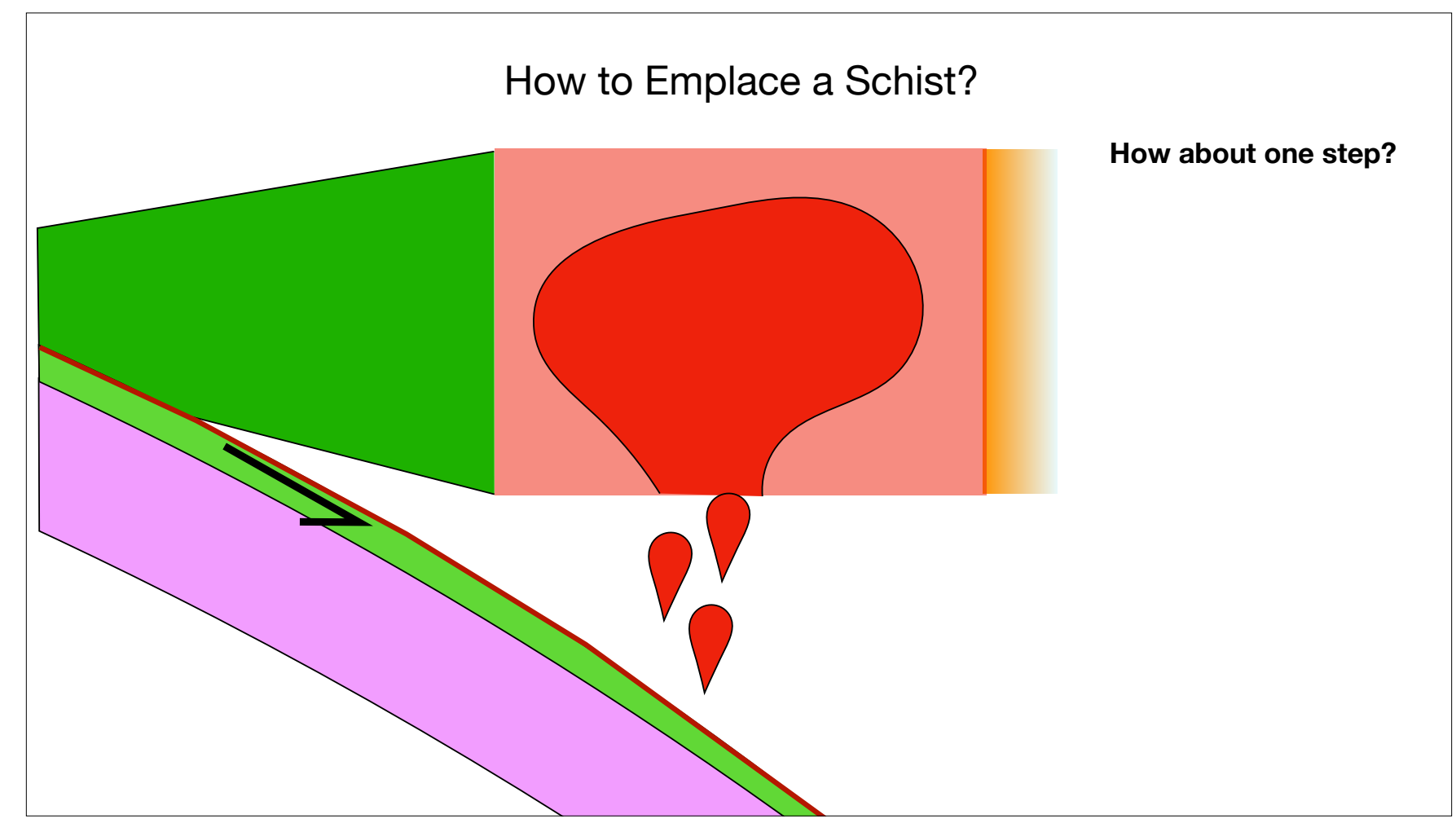

So let's cut out the middle man... 


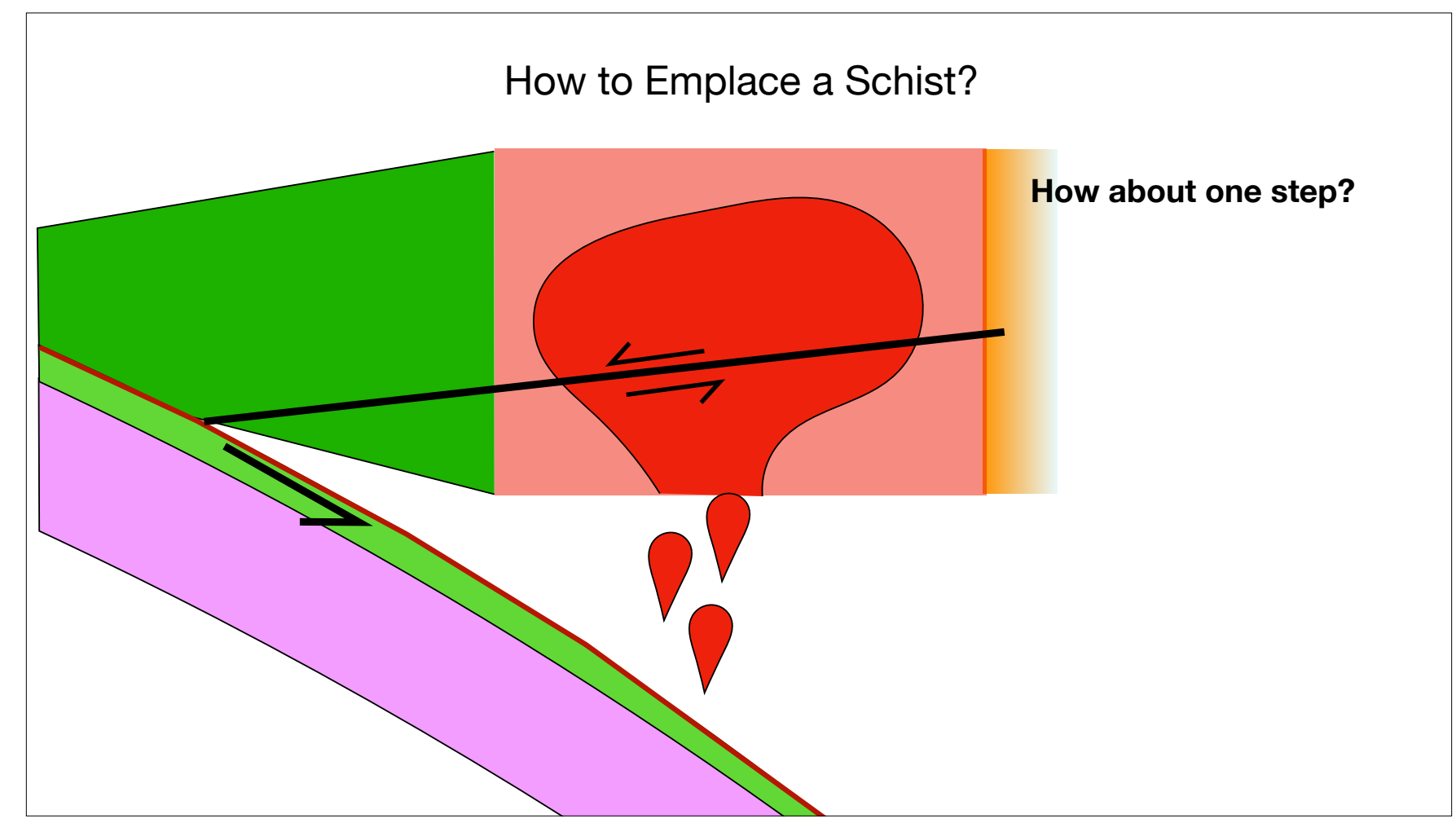

All these schists have normal faults at the top, it seems, so maybe start there? 


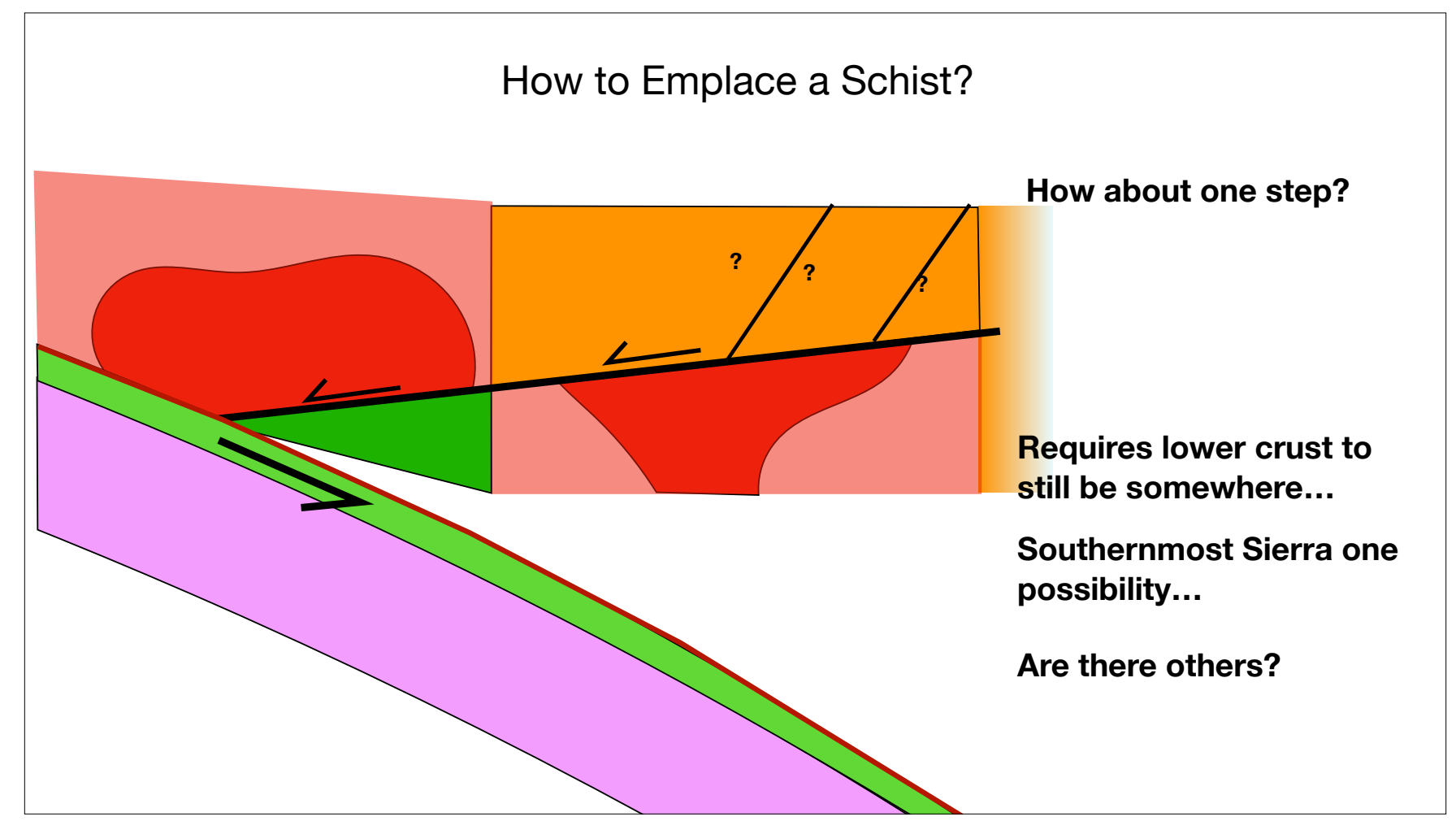

Also requires a big breakaway somewhere...that we don't seem to see. But note that small tilt would make these look like a thrust in some sense. Obviously this proposes that there are a bunch of structures not well recognized out there-but there are some things in favor of this goofy idea... 


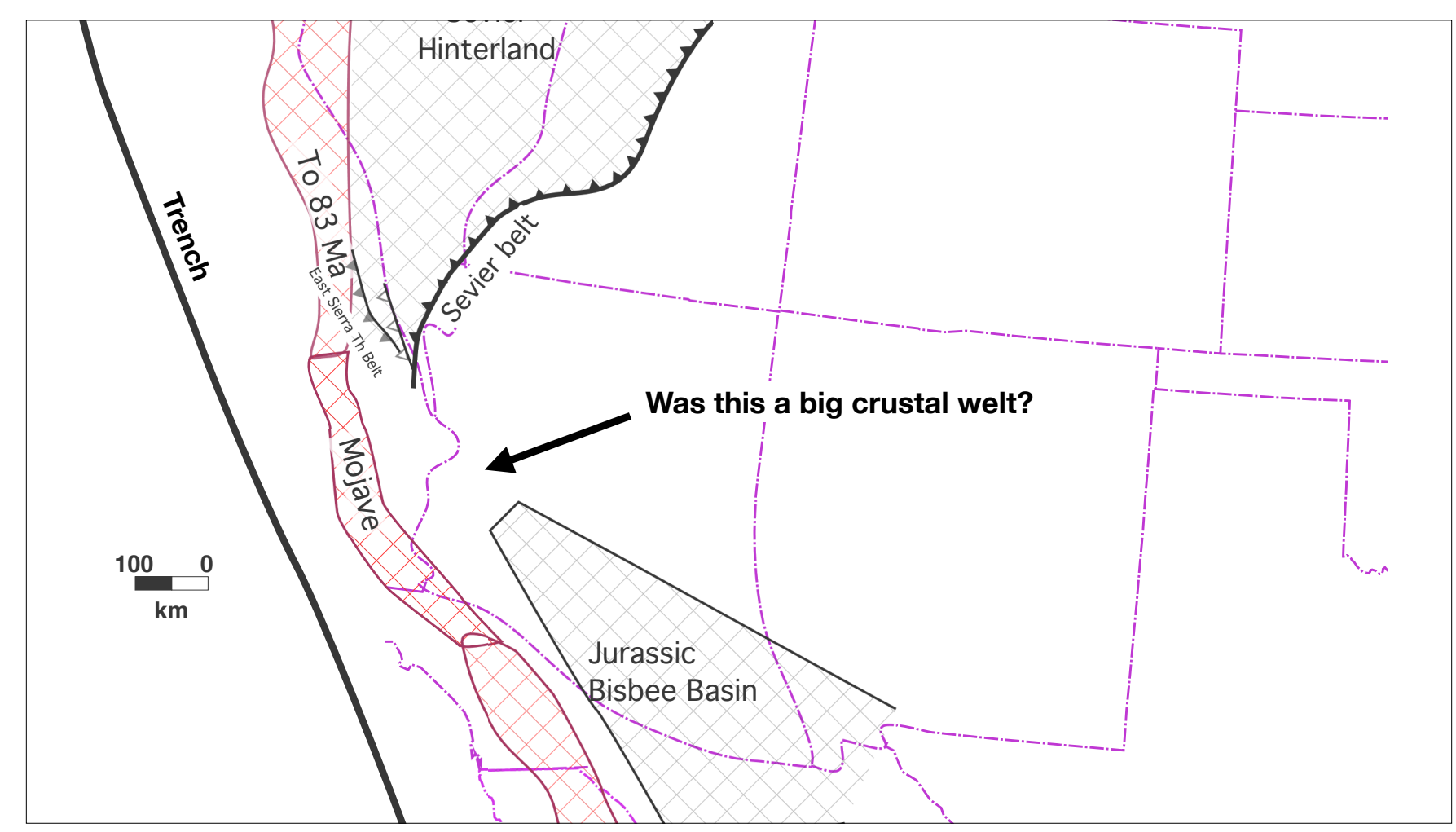

Big normal faults probably require a big pile of crust - or at least crust rising up really high... 


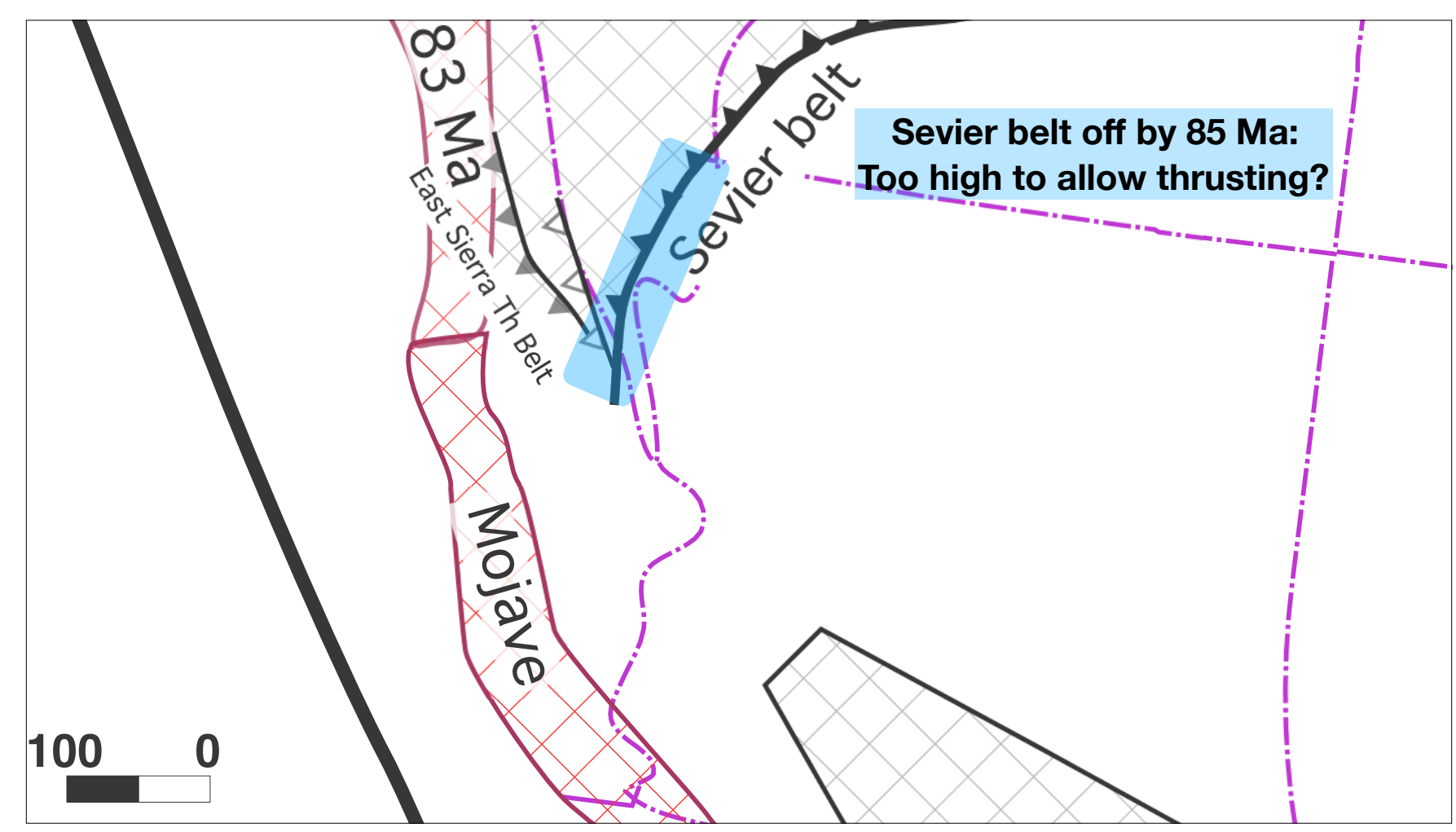

Would explain the shutdown of southern Sevier-just got too high (GPE acts to balance end loads much as Tibet is in extension at the surface). Also makes this as source for rivers to NE more palatable. 


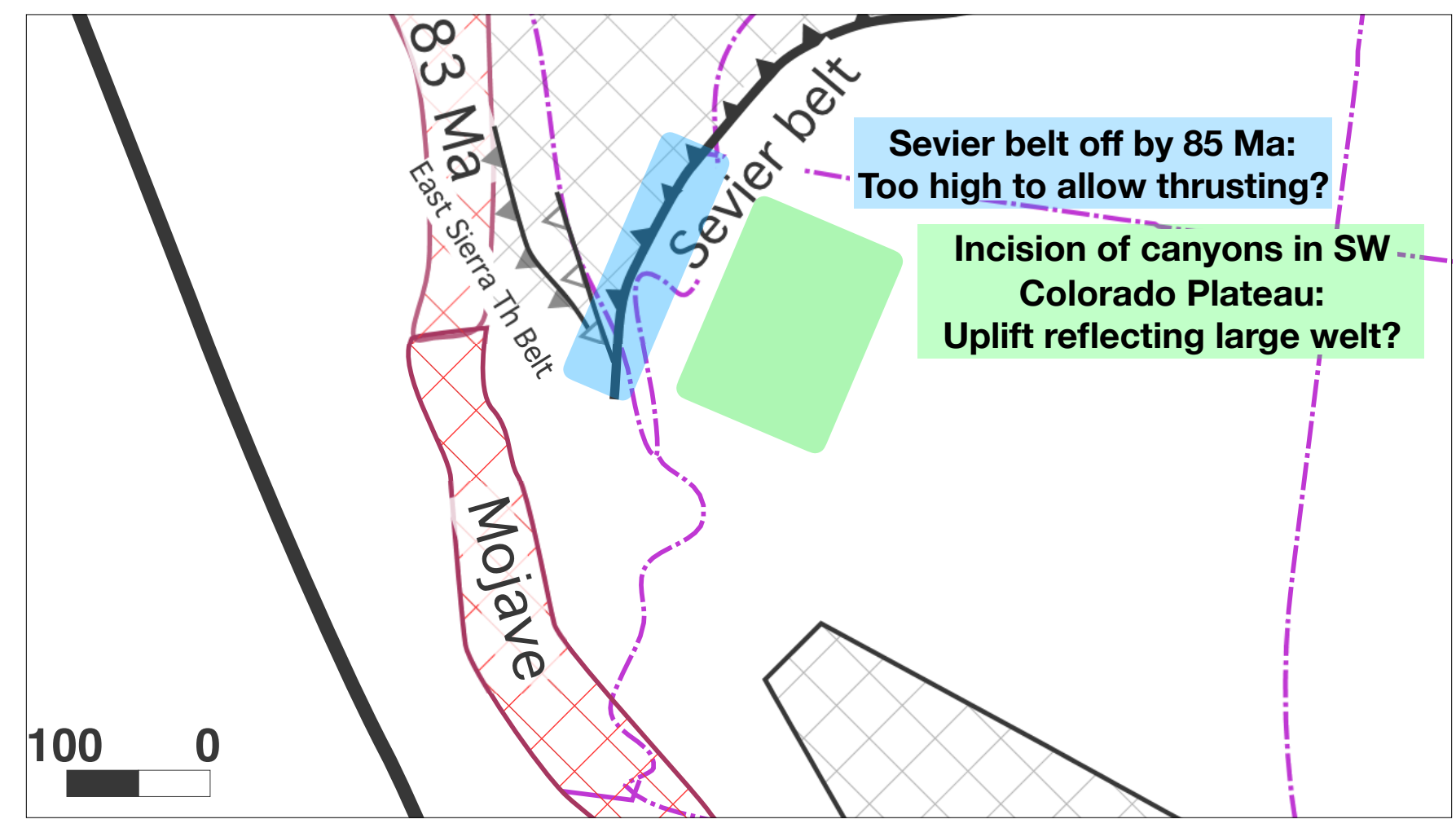

CP incision as dated by Flowers et al.; Music Mountain Formation of Richard Young is Paleocene; "California River" deposition of SE CA source into Uinta Basin is late Paleocene. 


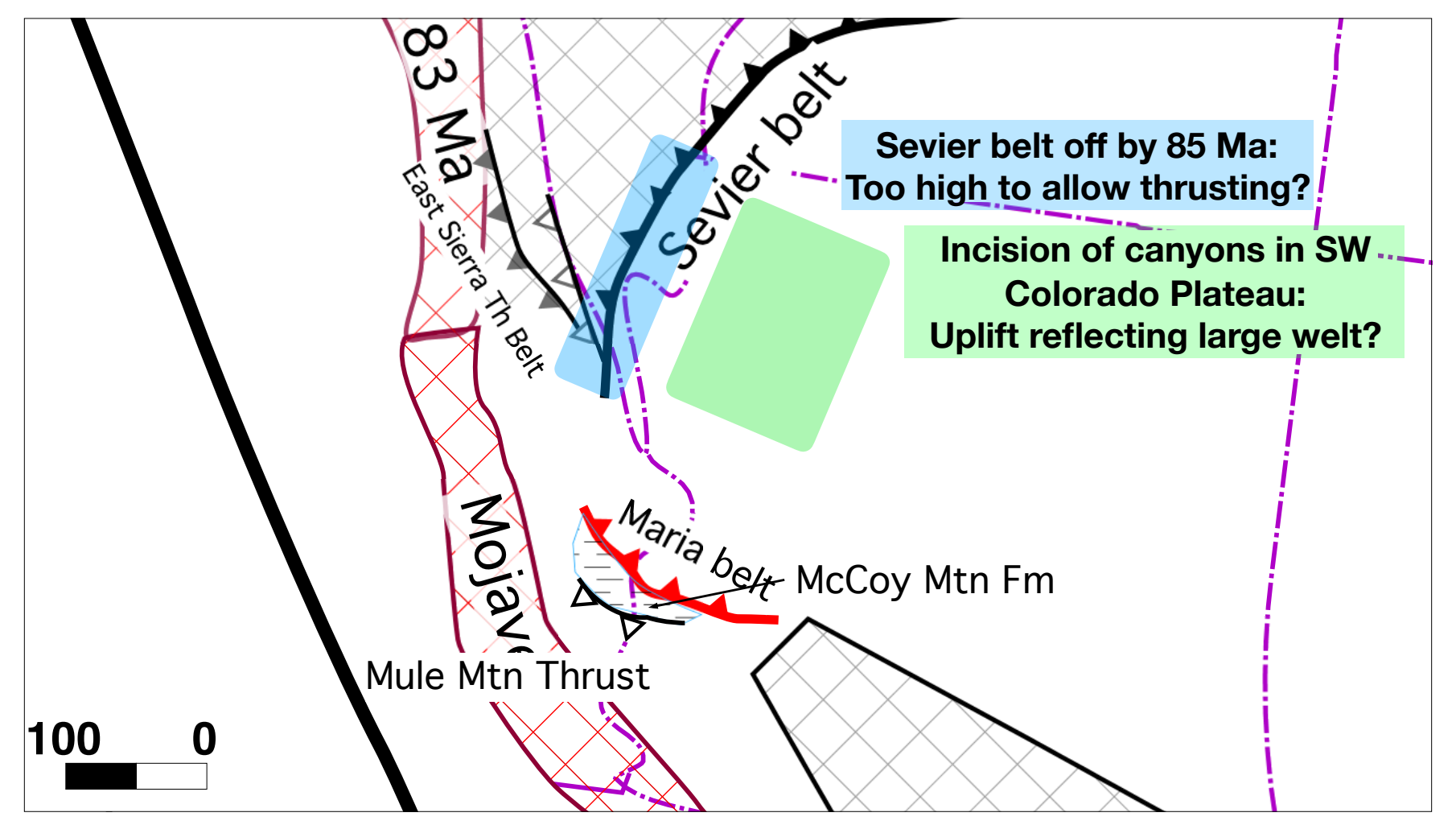

Also, could thrusts to south be from highland collapsing to the south initially? Faults in Maria belt reverse from compression to extension in this time frame. 


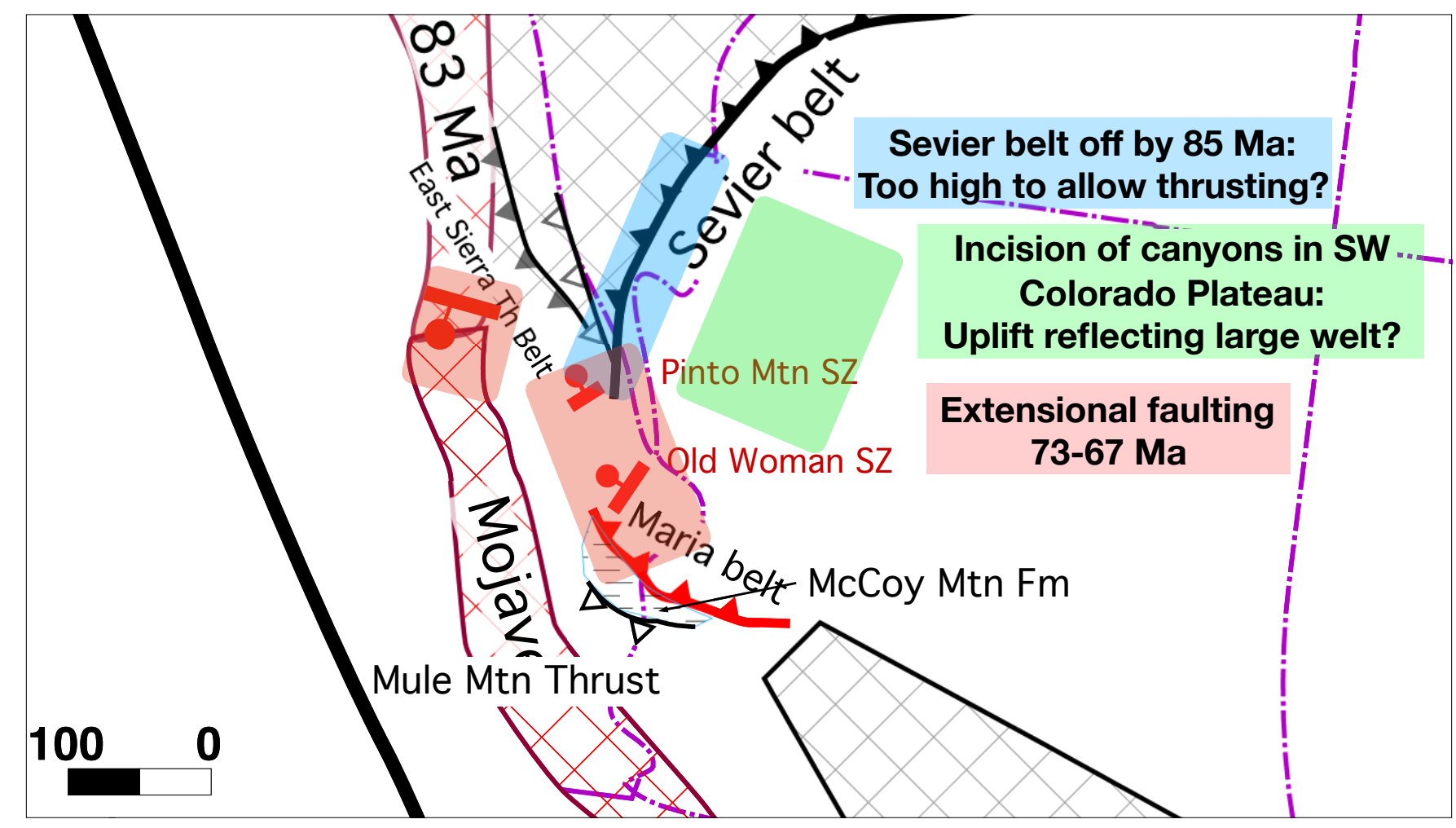

Several extensional faults in this area date to immediate post-arc timing.

Funeral Mtns also have 70-74 Ma extensional shear zone

Could this be from a plateau sitting under here? Timing an issue: would need to make young magmatism in Mojave on top of plateau. 


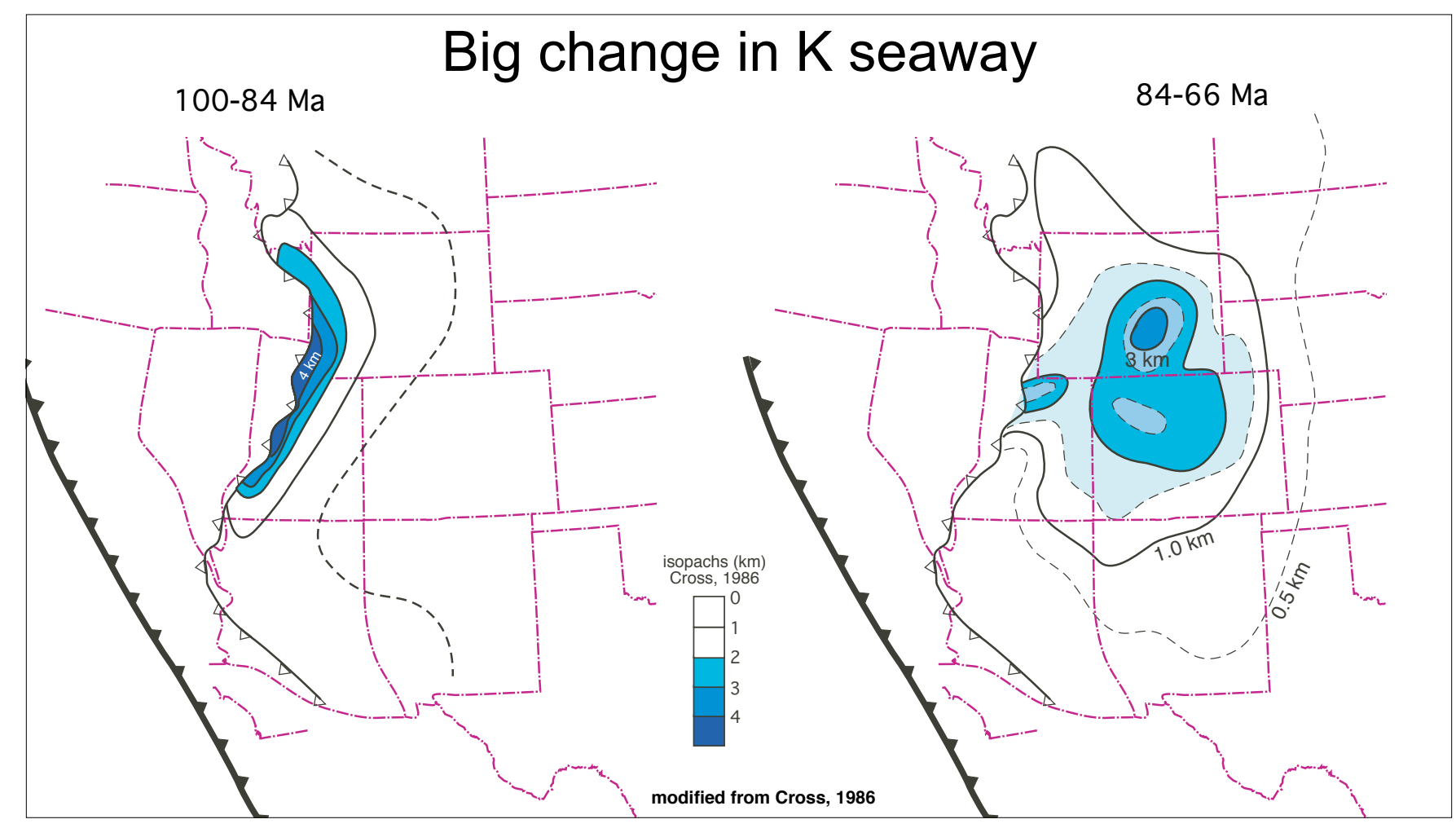

Another strike against a plateau is subsidence near this time in foreland...just a reminder of stuff published a few years back. 


\section{Helpful observations}

- Reconstruction of late $\mathrm{K}$ and Paleogene extension in Mojave

- Resolution of detrital zircon constraints on POR ages

- Do individual POR schist localities represent a very short event? Or was there long term accretion of material from the bottom?

- Are Mojave 72-83 Ma plutons the arc, or something special?

- Solid constraints on why Sierran arc went quiet for so long

What observations would get us the most understanding? This is my laundry list, but others are possible... 


\section{Conclusions}

- Continental acceleration certainly played a role in late $\mathrm{K}$

- Long duration shutdown of Sierran arc remains unclear

- arc migration into infertile mantle + longterm cooling?

- POR schists could reflect unusual extension more than unusual subduction

- Archean craton coupling with slab still better means of producing late $\mathrm{K}$ subsidence in foreland than plateau

\section{- Upper plate conditions matter!}

That last point is significant. Mojave looks special in large part because of its earlier Pz and Mz history -it was at the narrowest area of $\mathrm{K}$ deformation between an undeforming Colorado Plateau and the margin. Would seem odd that a plateau would find this odd spot and hit it just right-not impossible, of course, but odd. 